\title{
Assessment of Offshore Wave Energy Resources in Taiwan Using Long-Term Dynamically Downscaled Winds from a Third-Generation Reanalysis Product
}

\author{
Shih-Chun Hsiao ${ }^{1}\left(\mathbb{D}\right.$, Chao-Tzuen Cheng ${ }^{2}$, Tzu-Yin Chang ${ }^{2}$, Wei-Bo Chen ${ }^{2, *} \mathbb{C}$, Han-Lun Wu ${ }^{1}$, Jiun-Huei Jang ${ }^{1} \mathbb{C}$ \\ and Lee-Yaw Lin ${ }^{1}$ \\ 1 Department of Hydraulic and Ocean Engineering, National Cheng Kung University, Tainan City 70101, Taiwan; \\ schsiao@mail.ncku.edu.tw (S.-C.H.); hlwu627@mail.ncku.edu.tw (H.-L.W.); \\ jamesjang@mail.ncku.edu.tw (J.-H.J.); yaw@ncdr.nat.gov.tw (L.-Y.L.) \\ 2 National Science and Technology Center for Disaster Reduction, New Taipei City 23143, Taiwan; \\ ctcheng@ncdr.nat.gov.tw (C.-T.C.); geoct@ncdr.nat.gov.tw (T.-Y.C.) \\ * Correspondence: wbchen@ncdr.nat.gov.tw; Tel.: +886-2-8195-8612
}

check for updates

Citation: Hsiao, S.-C.; Cheng, C.-T.; Chang, T.-Y.; Chen, W.-B.; Wu, H.-L.; Jang, J.-H.; Lin, L.-Y. Assessment of Offshore Wave Energy Resources in Taiwan Using Long-Term Dynamically Downscaled Winds from a Third-Generation Reanalysis Product. Energies 2021, 14, 653. https://doi.org/10.3390/en14030653

Received: 22 December 2020 Accepted: 25 January 2021 Published: 28 January 2021

Publisher's Note: MDPI stays neutral with regard to jurisdictional clai$\mathrm{ms}$ in published maps and institutional affiliations.

Copyright: (C) 2021 by the authors. Licensee MDPI, Basel, Switzerland. This article is an open access article distributed under the terms and conditions of the Creative Commons Attribution (CC BY) license (https:// creativecommons.org/licenses/by/ $4.0 /)$.

\begin{abstract}
In this study, long-term wind fields during 1991-2010 from the Climate Forecast System Reanalysis (CFSR) were dynamically downscaled over Taiwan and its offshore islands at a $5 \mathrm{~km}$ horizontal resolution using the Weather Research and Forecasting (WRF) model. Simulations of the $10 \mathrm{~m}$ (above sea level) dynamically downscaled winds served as the atmospheric forcing for driving a fully coupled wave-circulation model. The sea states of the waters surrounding Taiwan during 1991-2010 were hindcasted to evaluate the offshore wave energy resources and optimal wave energy hotspots. This study reveals that the southeastern offshore waters of Taiwan and the Central Taiwan Strait exhibited the highest mean wave power density (WPD), exceeding $20 \mathrm{~kW} / \mathrm{m}$. The annual mean WPD, incidence of the hourly WPD greater than or equal to $4 \mathrm{~kW} / \mathrm{m}$, monthly variability index and coefficient of variation of the WPD indicated that the sea areas located between Green Island and Orchid Island $\left(\mathrm{OH} \_1\right)$, southeast of Orchid Island $\left(\mathrm{OH} \_2\right)$, south of the Hengchun Peninsula $\left(\mathrm{OH} \_3\right)$, and north of the Penghu Islands $\left(\mathrm{OH} \_4\right)$ were the optimal hotspots for deploying wave energy converters. The most energetic months were October for OH_1 and OH_2 and November for $\mathrm{OH} \_3$ and $\mathrm{OH} \_4$, while the wave power was weak from March to June for OH_1, OH_2 and $\mathrm{OH} \_3$ and in May for $\mathrm{OH} \_4$. The wave direction is prevailingly east-northeast for $\mathrm{OH} \_1, \mathrm{OH} \_2$ and $\mathrm{OH} \_3$ and nearly northeast for $\mathrm{OH} \_4$. These phenomena reveal that wave power in the waters offshore Taiwan is induced primarily by the northeast (winter) monsoon. The exploitable annual WPD was estimated to be $158.06,182.89,196.39$ and $101.33 \mathrm{MWh} / \mathrm{m}$ for OH_1,OH_2,OH_3 and $\mathrm{OH} \_4$, respectively.
\end{abstract}

Keywords: dynamical downscaling; reanalysis product; WRF model; wave energy resource; Taiwanese waters

\section{Introduction}

Offshore winds and waves have the greatest energy potential among all types of renewable energy, as the oceans cover a majority of the Earth's surface [1]. Wave energy is unique because it is the most concentrated form of renewable energy on Earth, with its power density being much higher than that of either wind or solar energy [2]; hence, wave energy converters have been installed and operated in many countries for decades [3]. Waves are created when wind moves over the ocean surface. Even small ripples on the ocean surface allow the wind to transfer some of its energy to the waves, causing the waves to grow from wind interactions over long distances. Globally, wave power resources have been estimated to reach $2.11 \pm 0.05 \mathrm{TW}$ (TeraWatt) [4]. The most appropriate sea areas for exploitation, featuring power densities of $60-70 \mathrm{~kW} / \mathrm{m}$, are found at medium-high 
latitudes with water depths exceeding $40 \mathrm{~m}$. However, even when the wave power is relatively invariable and more predictable than wind or solar power [5], compared to other established renewable energy sources, e.g., wind power, hydropower and solar power, wave power generation is not a widely employed commercial technology.

Although wave parameter measurements or global reanalysis products can be adopted to estimate tidal and wave power resources [6,7], numerical wind wave models are still popular tools for assessing ocean wave power both globally [4,8,9] and regionally [10-15]. Nevertheless, wind fields are commonly extracted from global reanalysis datasets, e.g., from the National Centers for Environmental Prediction (NCEP) Climate Forecast System Reanalysis (CFSR) or from the ERA-Interim and ERA5 archives of the European Centre for Medium-Range Weather Forecasts (ECMWF), to provide the wind forcing for driving a wind wave model. Unfortunately, even though this approach is convenient, the spatial resolution of global reanalysis winds (approximately tens of kilometers) might be insufficient for the accurate hindcasting of regional sea states.

For example, Gunn and Stock-Williams [4] estimated the global wave power using the outputs from an operational global wave prediction model, WaveWatch III (WW3), of the National Oceanic and Atmospheric Administration (NOAA). The outputs of WW3 provided by NOAA are at a temporal resolution of $3 \mathrm{~h}$ and a spatial resolution of 30 arcminutes (approximately $22.7 \mathrm{~km}$ ). Although the temporal and spatial resolutions of the global WW3 are coarser, its outputs are usable for global-scale wave power assessment. Gonçalves et al. [16] conducted a numerical study on the investigation of the wind wave energy distribution around the Canary Islands. The WW3 and SWAN (Simulating WAves Nearshore) models were adopted to generate sea states for the entire North Atlantic basin, and to determine the transformation of the offshore waves in the water surrounding the Canary Islands. ERA-Interim winds with a spatial resolution of $0.5^{\circ} \times 0.5^{\circ}$ and a $6 \mathrm{~h}$ temporal resolution were used to drive the WW3 and SWAN models. The winds from the ERA-Interim database are at a coarser spatial and temporal resolution, consequently resulting in an underestimation of regional wave power. Assessment of regional wave energy using numerical wind wave models is the current trend worldwide; therefore, it is necessary to apply the dynamic downscaling technique to rerun the global reanalysis product, and then more accurate and high-resolution wind forcing can be acquired for regional long-term wave modeling.

The island of Taiwan, with a population of 23.56 million people in December 2019, is surrounded by the western Pacific Ocean and the Taiwan Strait; geographically, Taiwan covers a land area of $35,989 \mathrm{~km}^{2}$ (excluding the land areas of its offshore islands) and a territorial sea area of $35,683 \mathrm{~km}^{2}$ (including the sea areas around Green Island, Orchid Island and the Penghu Islands). According to the statistical data issued by the Ministry of Economic Affairs in Taiwan [17], the total electricity generating capacity of Taiwan was $274,058 \mathrm{GWh}$ in 2019 , of which fuel-fired power accounted for $81.47 \%(223,279.74 \mathrm{GWh})$, nuclear power accounted for $11.80 \%(32,323.4 \mathrm{GWh})$, renewable power accounted for $5.56 \%$ $(15,247.5 \mathrm{GWh})$, and hydroelectric power accounted for 1.17\% (3208.1 GWh). Regarding renewable energy, only waste-to-energy, wind power and solar power are currently utilized in Taiwan. Therefore, it is urgent for Taiwan to exploit the energy resources from the ocean, e.g., tidal currents and wave energy, because the ocean surrounding Taiwan provides a plentiful, renewable, and environmentally friendly source of energy.

The present study contributes novel insights into the improvement of long-term wind fields for assessing wave energy by using a high-resolution dynamical downscaling technique. This paper is organized as follows: Section 2 describes the wind forcing, observational data, bathymetry data and fully coupled wave circulation model that were used in the present study. Section 3 presents comparisons between the hindcasts and measurements for the significant wave height $(\mathrm{SWH})$, peak wave period and wave direction adopting wind fields from a third-generation reanalysis product and from the dynamically downscaled wind. Section 4 provides not only wave energy assessments and the identification of possible hotspots for wave energy based on a hindcast of sea states over twenty 
years in the offshore waters of Taiwan, but also presents a discussion of the hindcasting results. Finally, a summary and conclusions are presented in Section 5.

\section{Materials and Methods}

\subsection{Meteorological Forcing Data}

The NCEP CFSR is a global, high-resolution, coupled atmosphere-ocean-land surfacesea ice system [18] that serves as a third-generation reanalysis product providing the best available estimates of the global-scale atmospheric conditions from 1979 to March 2011. Hourly wind data $10 \mathrm{~m}$ above sea level with a spatial resolution of $0.312^{\circ}$ are available on the website of the Research Data Archive Computational and Information System Laboratory of the National Center for Atmospheric Research (NCAR). Thus, hourly CFSR data from 1991 to 2010 were obtained from NCAR to serve as the boundary conditions for regional numerical atmospheric modeling.

The Weather Research and Forecasting (WRF) model [19] is a numerical atmospheric model designed for both research and numerical weather prediction. The WRF model, which is officially supported by NCAR, has become the most widely used weather prediction model in the world, especially for forecasting severe meteorological events such as heavy rainfall $[20,21]$, typhoons or tropical cyclones [22,23], and thunderstorms [24,25]. Furthermore, the WRF model can focus on regional domains with resolutions beyond what most users can attain using global models [26]. The WRF model with three nested domains was applied in the present study to dynamically downscale the original CFSR data from 1991 to 2010 . The parent domain (D01) covers $-5.35^{\circ} \mathrm{N}-42.93^{\circ} \mathrm{N}$ and $77.91^{\circ} \mathrm{E}-159.99^{\circ} \mathrm{E}$ with a $45 \mathrm{~km}$ grid spacing; the first nested domain (D02) lies between $5.13^{\circ} \mathrm{N}-39.39^{\circ} \mathrm{N}$ and $103.65^{\circ} \mathrm{E}-138.41^{\circ} \mathrm{E}$ with a $15 \mathrm{~km}$ grid spacing; and the second nested domain (D03) extends over $14.32^{\circ} \mathrm{N}-32.12^{\circ} \mathrm{N}$ and $111.56^{\circ} \mathrm{E}-131.43^{\circ} \mathrm{E}$ at a $5 \mathrm{~km}$ grid spacing. The wind field derived from the regional WRF model is called CFSR_5 $\mathrm{km}$ in the present study. The individual extents of the three domains with varying spatial resolutions in the WRF model are shown in Figure 1. Notably, one-way nesting technique in the WRF model was used in the present study. The parent domain (d01) runs first and then the nest domain (d02) runs afterward with the parent domain data. The same approach is also employed between $\mathrm{d} 02$ and its nest domain (d03). At each time step of the coarse grid domain, the outputs from the coarse grid domain are passed through the specified lateral boundary conditions of the WRF model.

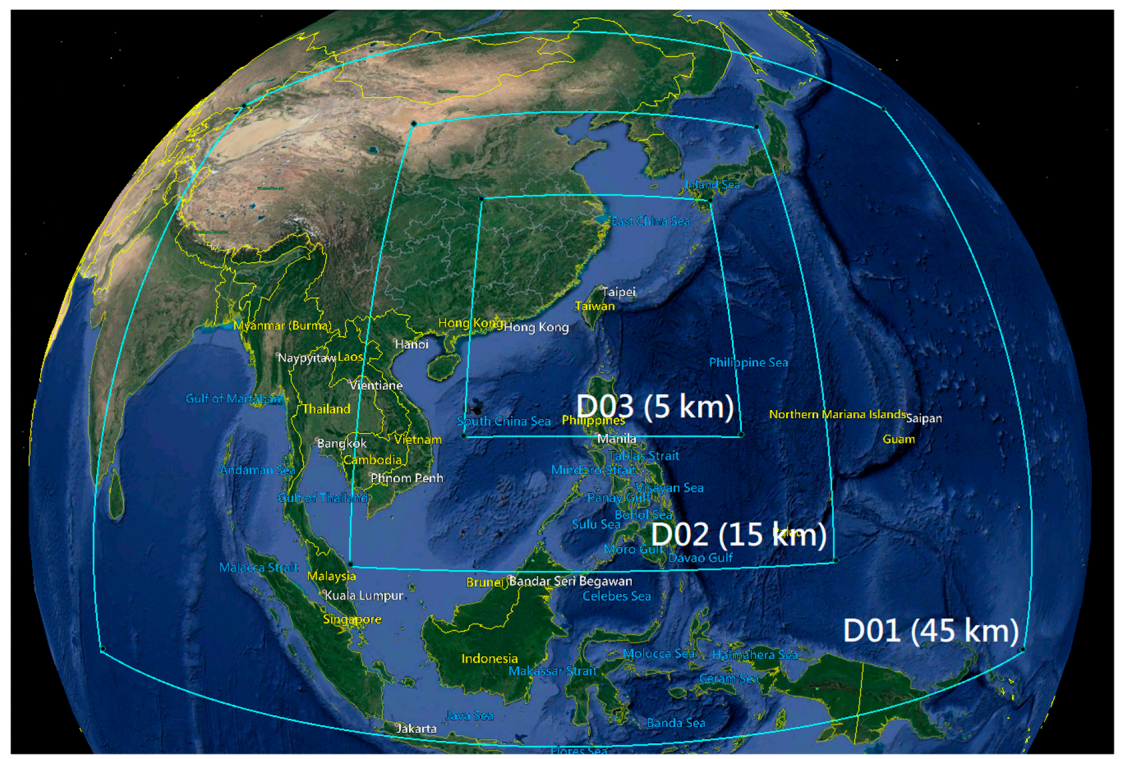

Figure 1. Extents of the Weather Research and Forecasting (WRF) model with grid spacings of approximately $45 \mathrm{~km}$ for Domain 1 (D01), approximately $15 \mathrm{~km}$ for Domain 2 (D02) and approximately $5 \mathrm{~km}$ for Domain 3 (D03). 


\subsection{Description and Configuration of SCHISM-WWM-III}

The Semi-Implicit Cross-Scale Hydroscience Integrated System Model (SCHISM) was utilized to hindcast the long-term tides and currents in the waters surrounding Taiwan. SCHISM, which was originally implemented by [27], is derived from the SemiImplicit Eulerian-Lagrangian Finite-Element (SELFE) model [28] with many improvements. The shallow water equations are solved by employing a highly efficient and accurate finite-element/finite-volume method with the Eulerian-Lagrangian algorithm and the application of the hydrostatic and Boussinesq approximations. The stability restrictions avoid constraints associated with the Courant-Friedrichs-Lewy (CFL) condition by applying semi-implicit numerical schemes to the governing equations. Additionally, using the Eulerian-Lagrangian method for the nonlinear advection terms further relaxes the stability constraints of the numerical model. SCHISM introduces the no-mode-splitting technique, which eliminates the numerical errors derived from an internal-external mode splitting procedure [29]. Consequently, owing to their high efficiency and accuracy, the SELFE model and SCHISM have been widely used for investigating the transport and fate of fecal coliform contamination in a tidal estuarine system [30], predicting coastal inundation [31,32] and riverine flash floods [33], and assessing the tidal current energy in nearshore waters [34]. Compared to a three-dimensional model, a two-dimensional model requires fewer computing resources and shorter model execution times; in addition, the hydrodynamics in a large-scale ocean can be well simulated by a two-dimensional model. Thus, because a two-dimensional model is preferred over a three-dimensional model for long-term wind wave modeling, SCHISM-2D (a depth-integrated version of SCHISM) was employed in the present study. A Manning coefficient of 0.025 and a time step of $120 \mathrm{~s}$ were prescribed in SCHISM-2D based on the seafloor material in Taiwanese waters reported by previous studies [35-38].

A third-generation, state-of-the-art spectral surface wave model, namely, the Wind Wave Model-III (WWM-III), was adopted to hindcast the sea state in the nearshore and offshore waters of Taiwan. Phase-averaged spectral wave models have the ability to simulate wave parameters on the free surface of a large water body [39]. WWM-III is a derivative work of the original WWM-I [40] that solves the wave action equation (WAE) by using new numerical schemes and revised physics on an unstructured grid [41]. A fractional time step method [42] was applied in WWM-III to integrate the various terms of the WAE, while the integration in spectral space was accomplished through the ultimate quickest approach [43]. The number of frequency bins was 36, and the frequency limits for the discrete wave period were in the range of $0.03 \mathrm{~Hz}$ to $1.0 \mathrm{~Hz}$. The directions for the simulation were divided into 36 directional bins with a minimum and maximum of $0^{\circ}$ and $360^{\circ}$, respectively. A peak enhancement factor of 3.3 based on the report from the Joint North Sea Wave Project (JONSWAP, [44]), a wave breaking coefficient of 0.78 and a bottom friction coefficient of 0.067 are preset in WWM-III.

Utilizing the different time steps for ocean and wind wave models and sharing the same numerical mesh are better methods to enhance the computing efficiency of a wavecirculation coupled modeling system; for this reason, a time step of $600 \mathrm{~s}$ was chosen for WWM-III. In other words, SCHISM-2D and WWM-III exchanged the wind speed, depth-integrated tidal current, water surface elevation and wave radiation stress on each grid every 5 hydrodynamic time intervals. Details on the coupling procedure for the SCHISM-WWM-III coupled modeling system are available in [45]. Due to its high numerical efficiency and robust matrix solver, SCHISM-WWM-III has been successfully implemented to investigate wave power resources and produce potential storm wave hazard maps for Taiwan [35,36], evaluate the wind forcing effect on storm wave hindcasting [37], quantify storm tide-induced nonlinear interactions [38], simulate extreme waves caused by a super typhoon [46,47], and evaluate wave-current interactions [48].

A large computational domain is essential for long-term wave climate hindcasting, especially when hindcasting typhoon waves and surges. Therefore, the domain from $111^{\circ} \mathrm{E}$ to $135^{\circ} \mathrm{E}$ and $18^{\circ} \mathrm{N}$ to $30^{\circ} \mathrm{N}$ was created for SCHISM-WWM-III. This wide area 
has been shown to be sufficient for simulating typhoon-driven sea states in the offshore waters of Taiwan. The entire computational domain comprised 168,829 unstructured grids and 327,955 triangular elements (as shown in Figure 2a). A fine mesh with a resolution of approximately $200 \mathrm{~m}$ was distributed along the coast of Taiwan (as shown in Figure $2 b$ ) and its offshore islands (as shown in Figure 2c), while a coarse mesh with a resolution of approximately $40 \mathrm{~km}$ was configured in the open ocean far from the coastal zone. The fine mesh developed in the present study is able to characterize the surf zones and shallow waters $[46,48-51]$. Notably, the performance of the JONSWAP spectrum in the simulation of long-term or extreme sea states in the offshore waters of Taiwan was impressive, and this spectrum has been widely used to simulate wave conditions worldwide [35-38,46-48,52], although the JONSWAP spectrum was originally applied in the North Sea.
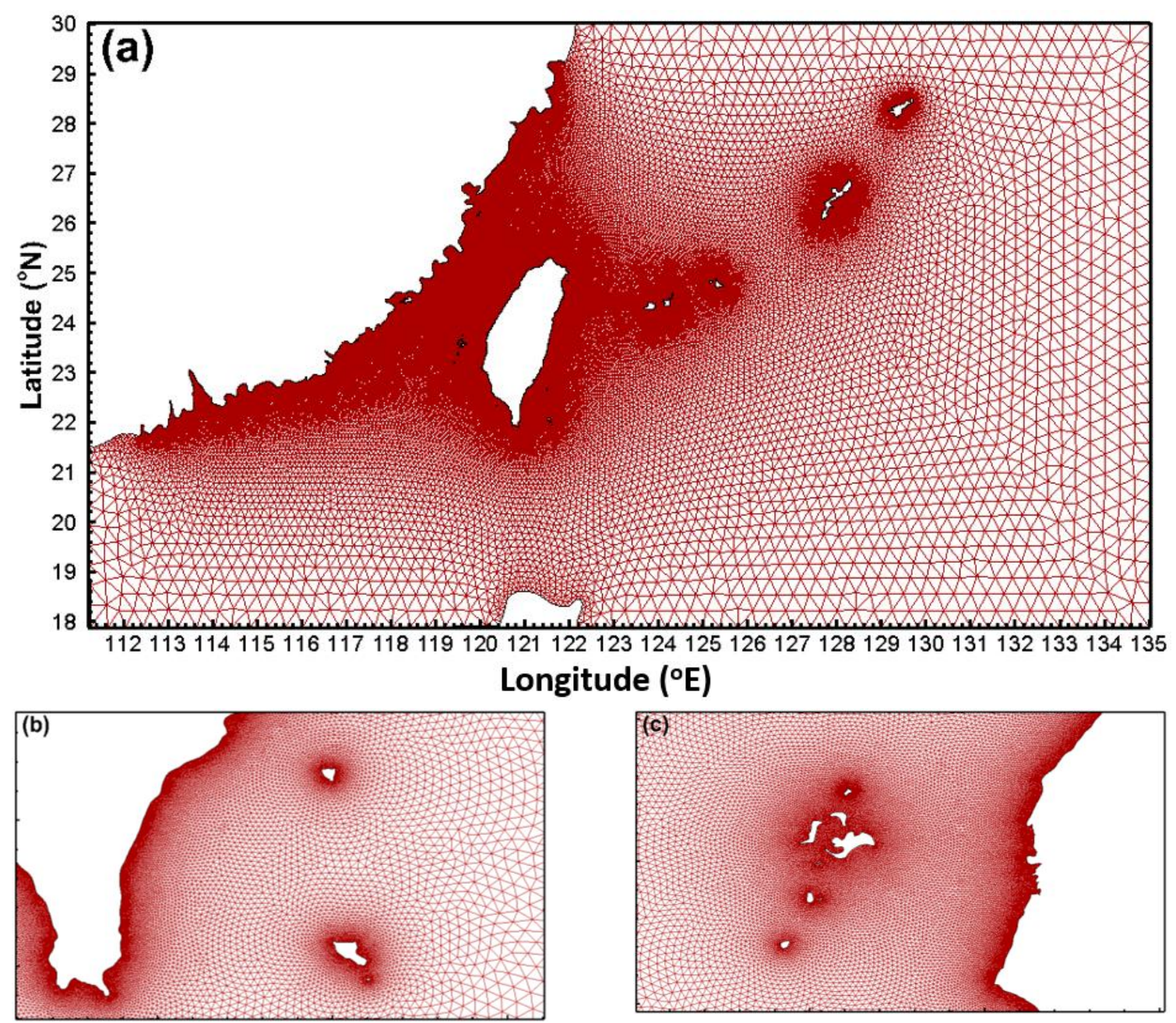

Figure 2. (a) Unstructured grid mesh for the whole computational domain, (b) magnified view of the high-resolution unstructured grid mesh for Green Island and Orchid Island, and (c) magnified view of the high-resolution unstructured grid mesh for the Penghu Islands.

The gridded bathymetric data for SCHISM-WWM-III were constructed by global-scale and local-scale bathymetric datasets. The GEBCO_2019 grid with a 15-arcsecond spatial resolution is the latest global-scale bathymetric dataset, which was released by the General Bathymetric Chart of the Oceans (GEBCO) and established through the Nippon FoundationGEBCO Seabed 2030 Project. The local-scale digital elevation model was obtained from the Department of Land Administration and the Ministry of the Interior in Taiwan. The local-scale dataset covers the region from $100^{\circ} \mathrm{E}$ to $128^{\circ} \mathrm{E}$ and from $4^{\circ} \mathrm{N}$ to $29^{\circ} \mathrm{N}$ with only a $200 \mathrm{~m}$ spatial resolution. The bottom elevation for each grid in SCHISM-WWM-III 
was interpolated by the inverse distance weighting (IDW) method from a combination of these two gridded datasets (as shown in Figure 3a). The IDW formula is:

$$
p_{e}(x, y)=\frac{\sum_{i=1}^{n} \frac{1}{d_{i}} p_{m}\left(x_{i}, y_{i}\right)}{\sum_{i=1}^{n} \frac{1}{d_{i}}}
$$

where $p_{e}(x, y)$ is the value to be estimated (the bathymetric grid in SCHISM-WWM-III), $p_{m}(x, y)$ is the known value (the bathymetric grids in the gridded datasets), and $d_{i}$ is the distance from the data point to the estimated point.
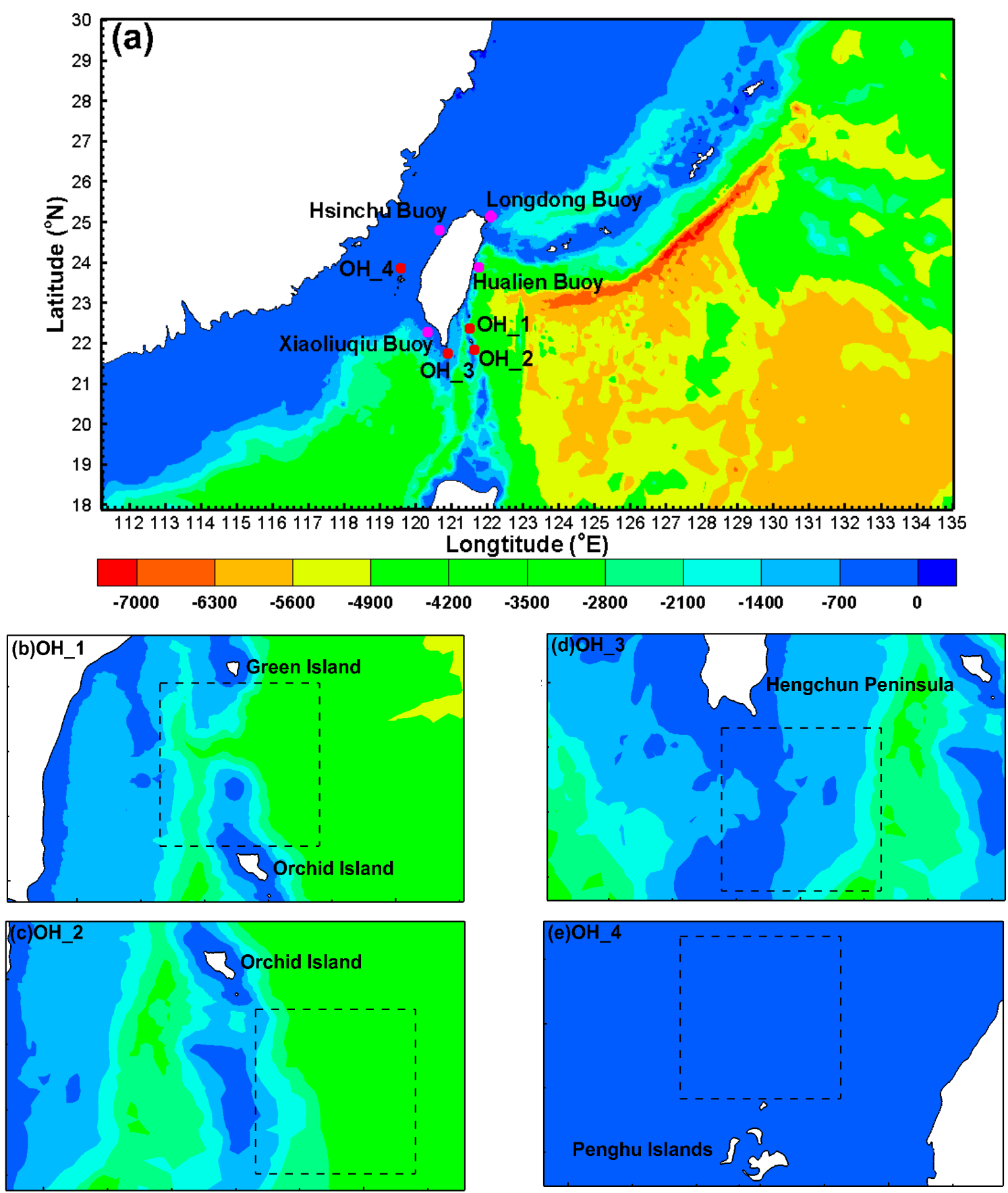

Figure 3. (a) Bathymetry for the whole computational domain and (b) magnified views of the bathymetry for offshore hotspot $\mathrm{OH} \_1$, (c) $\mathrm{OH} \_2$, (d) $\mathrm{OH} \_3$ and (e) $\mathrm{OH} \_4$. 
All the initial conditions, such as sea surface elevation and horizontal velocity, on each grid of SCHISM-WWM-III were set equal to zero, and the first 15 days were taken as the spin-up time for SCHISM-WWM-III. The tidal boundary conditions of SCHISMWWM-III are M2, S2, N2, K2, K1, O1, P1 and Q1 tidal constituents, which were derived from a regional inverse tidal model (China Seas and Indonesia, [53]). The 3-h wave spectral from operational global WW3 of NOAA was applied to the wave boundary conditions for SCHISM-WWM-III.

\subsection{Wave Buoy Data}

Hourly measurements of the $\mathrm{SWH}$, peak wave period and wave direction recorded at four wave buoys by the Central Weather Bureau (CWB) of Taiwan in 2010 were secured to evaluate the hindcasting performance of SCHISM-WWM-III using the wind fields from CFSR and CFSR_5km. The four wave buoys shown in Figure 3a, namely, the Longdong, Hualien, Hsinchi and Xiaoliuqiu buoys, are located in the northern, eastern, western and southern waters of Taiwan, respectively.

\subsection{Computation of Offshore Wave Energy}

The wave power per unit crest length in the direction of wave propagation, i.e., the wave power density (WDP), can be obtained through the spectral output of the wind wave model. The WPD $(P)$ formula is given as:

$$
P=\rho g \int_{0}^{2 \pi} \int_{0}^{\infty} c_{g}(\sigma, d) S(\sigma, \theta) \mathrm{d} \sigma \mathrm{d} \theta
$$

where $\rho$ is the density of seawater, $g$ is the gravitational constant of acceleration, $\sigma$ is the wave relative angular frequency, $\theta$ is the wave propagation direction, $S(\sigma, \theta)$ is the directional wave variance density spectrum, and $d$ is the depth of water. In addition, $c_{g}(\sigma, \theta)$ is the wave group velocity, which can be expressed as:

$$
c_{g}(\sigma, d)=\frac{g}{4 \pi \sigma}\left[1+\frac{2 \kappa d}{\sinh (2 \kappa d)}\right] \tanh (\kappa d)
$$

where $\kappa=2 \pi / \lambda$ is the wavenumber and $\lambda$ is the wavelength. In deep water, i.e., $d>\lambda / 2$, Equation (3) can be simplified to $c_{g}(\sigma, d)=g / 4 \pi \sigma$. Hence, Equation (2) is rewritten as:

$$
P=\frac{\rho g^{2}}{4 \pi} \int_{0}^{2 \pi} \int_{0}^{\infty} \sigma^{-1} S(\sigma, \theta) \mathrm{d} \sigma \mathrm{d} \theta
$$

The $n$th order spectral moment $(m)$ is defined as:

$$
m_{n}=\int_{0}^{2 \pi} \int_{0}^{\infty} \sigma^{n} S(\sigma, \theta) \mathrm{d} \sigma \mathrm{d} \theta
$$

The SWH $H_{s}$ and the energy period $T_{e}$ in terms of the spectral moment are expressed as:

$$
\begin{gathered}
T_{e}=\frac{m_{-1}}{m_{0}}=\frac{\int_{0}^{2 \pi} \int_{0}^{\infty} \sigma^{-1} S(\sigma, \theta) \mathrm{d} \sigma \mathrm{d} \theta}{\int_{0}^{2 \pi} \int_{0}^{\infty} S(\sigma, \theta) \mathrm{d} \sigma \mathrm{d} \theta} \\
H_{S}=4\left(m_{0}\right)^{1 / 2}=4\left(\int_{0}^{2 \pi} \int_{0}^{\infty} S(\sigma, \theta) \mathrm{d} \sigma \mathrm{d} \theta\right)^{1 / 2} .
\end{gathered}
$$


Substituting Equations (5)-(7) into Equation (4), a simple formula for calculating the WPD $(P)$ can be obtained:

$$
P=\frac{\rho g^{2}}{64 \pi} H_{s}^{2} T_{e} .
$$

$\rho$ is assumed to be $1025 \mathrm{~kg} / \mathrm{m}^{3}$ in the present study, and thus, Equation (8) becomes:

$$
P(\text { kilowatt } / \text { meter }, \mathrm{kW} / \mathrm{m})=0.49 H_{s}^{2} T_{e} \text {. }
$$

$T_{e}$ is best evaluated through other variables because it is rarely specified by the measurements of wave parameters. Thus, the peak period $T_{p}$ was adopted to calculate the WPD through multiplication by the coefficient $\alpha$ :

$$
T_{e}=\alpha T_{p}
$$

in which $\alpha=0.9$ was adopted from the standard JONSWAP spectrum with a peak enhancement factor of $\gamma=3.3[35,54-58]$. Therefore, the theoretical WPD at an arbitrary point on the computational mesh was estimated by means of the following formula:

$$
P(\text { kilowatt } / \text { meter, } \mathrm{kW} / \mathrm{m})=0.44 H_{s}^{2} T_{p},
$$

The effects of wave refraction and shoaling on wave power can be ignored since the continental shelf of Taiwan is small. Accordingly, Equation (11) is sufficient to represent the magnitude of the offshore WPD in Taiwan [35,57]. Finally, the total annual wave energy per unit length can be produced for a given time interval:

$$
E_{t}(\text { kilowatt hour } / \text { meter, } \mathrm{kWh} / \mathrm{m})=\sum_{i} P_{i} \times \Delta t_{i}
$$

More details regarding Equations (2)-(8) can be found in [59].

\subsection{Metrics for Determining the Optimal Wave Energy Hotspots}

Four criteria, i.e., the long-term annual mean WPD, incidence of exploitable wave power, monthly variability index (MVI) and coefficient of variation (COV), were used to identify the optimal wave energy hotspots in the offshore waters of Taiwan. Offshore sea areas are considered to be optimal hotspots for the deployment of wave energy converters as long as there is an abundant WPD and a higher incidence of exploitable wave power but a lower MVI and COV. Exploitable wave power is defined as a WPD equal to or greater than $4 \mathrm{~kW} / \mathrm{m}$ in the present study. The spatiotemporal variabilities were characterized by adopting the MVI and COV:

$$
\mathrm{MVI}=\frac{P_{\max \_ \text {mavg_lt }}-P_{\min \_ \text {mavg_l } l t}}{P_{\text {yavg_l }} l t},
$$

where $P_{\text {max_mavg_lt }}$ and $P_{\text {mix_mavg_lt }}$ are the maximum and minimum long-term (20-year) monthly average WPDs, respectively, and $P_{\text {yavg_lt }}$ is the long-term (20-year) yearly mean WPD.

$$
\mathrm{COV}=\frac{\sigma_{\text {wo }}}{P_{\text {yavg_l }} l t},
$$

where $\sigma_{w p}$ is the standard deviation of the long-term (20-year) average WPD.

\section{Results}

\subsection{Hindcast of Wave Parameters Using the CFSR and CFSR_5km Wind Fields}

To confirm that the regional dynamically downscaled wind fields are superior to the global reanalysis fields in hindcasting wave parameters, hourly winds from the original CFSR and from CFSR_5 km were employed as atmospheric boundary conditions for 
SCHISM-WWM-III to reproduce the SWHs, peak wave periods and wave directions in the waters surrounding Taiwan in 2010. Figure 4a-h demonstrates scatter plots of the hindcasted SWHs versus the measured SWHs for the Longdong (Figure 4a,e), Hualien (Figure $4 \mathrm{~b}, \mathrm{f}$ ), Hsinchu (Figure $4 \mathrm{c}, \mathrm{g}$ ) and Xiaoliuqiu (Figure $4 \mathrm{~d}$,h) buoys using the CFSR (Figure $4 \mathrm{a}-\mathrm{d}$ ) and CFSR_5 $\mathrm{km}$ winds (Figure $4 \mathrm{e}-\mathrm{h}$ ). The largest differences for the SWH (hindcast minus measurement) range between 6 and $8 \mathrm{~m}$ are detected at the Longdong buoy when SCHISM-WWM-III was given the wind fields from the CFSR (Figure 4a). The SWH differences were always within $\pm 2 \mathrm{~m}$ at the Hualien buoy due to the utilization of the CFSR_5km winds. The scatter plots of the hindcasted versus measured peak wave periods for the different wave buoys are shown in Figure $5 \mathrm{a}-\mathrm{h}$ (Figure $5 \mathrm{a}$,e is for the Longdong buoy, Figure $5 b, f$ is for the Hualien buoy, Figure $5 c, g$ is for the Hsinchu buoy, and Figure $5 d, h$ is for the Xiaoliuqiu buoy). The differences in the peak wave period reached $4-6 \mathrm{~s}$ at the Longdong and Hualien buoys due to the presence of CFSR winds in SCHISM-WWM-III (Figure 5a,b), while introducing the CFSR_5 $\mathrm{km}$ wind fields into SCHISM-WWM-III led to peak wave period differences of only $\pm 2 \mathrm{~s}$. The differences in the wave direction between the hindcasts and measurements using different wind boundary conditions are illustrated in Figure 6a-h (Figure 6a,e is for the Longdong buoy, Figure $6 \mathrm{~b}, \mathrm{f}$ is for the Hualien buoy, Figure $6 c, g$ is for the Hsinchu buoy, and Figure $6 \mathrm{~d}, \mathrm{~h}$ is for the Xiaoliuqiu buoy). These scatter plots show that the wave directions hindcasted by the CFSR_5 $\mathrm{km}$ winds are more reliable than those hindcasted by the CFSR winds. Tables 1-3 summarize the percentages of the model-data differences for different classes and buoys owing to the adoption of winds from CFSR and CFSR_5km. According to the statistical results from these tables, the combination of SCHISM-WWM-III and winds from CFSR_5km exhibits a superior overall hindcasting performance for the SWHs, peak wave periods and wave directions. Thus, the CFSR_5km winds served as the meteorological forcing of SCHISM-WWM-III for the long-term wave parameter hindcasting in the present study.

\subsection{Spatial Distribution of the Annual Average Wave Power}

SCHISM-WWM-III outputted the hourly SWH and peak wave period in each grid, and then the WPD was computed by means of Equation (11). The spatial distributions of the offshore annual average WPD (in $\mathrm{kW} / \mathrm{m}$ ) in the Taiwanese waters from 1991 to 2000 and from 2001 to 2010 are shown in Figures 7 and 8, respectively. The most energetic sea areas are located along the southern and southeastern waters of Taiwan, with the annual mean WPD reaching 28-30 kW/m in 1991 (Figure 7). The sea area in the Central Taiwan Strait (i.e., the Penghu Islands) is another sea area rich in wave power. The highest annual mean WPD was $26 \mathrm{~kW} / \mathrm{m}$ in 2000 (Figure 7). The annual average WPD was more abundant in 1991, 1992, 1994, 1996, 1999, 2000, 2004, 2005, 2007 and 2008, while 2002 had the smallest annual mean WPD (Figure 8). The offshore WPD in each grid was averaged over 20 years from 1991 to 2010, and the corresponding spatial distribution is presented in Figure 9. The offshore areas lying between Green Island and Orchid Island (Figure $3 b$ ), southeast of Orchid Island (Figure 3c), south of the Hengchun Peninsula (Figure 3d), and north of the Penghu Islands (as shown in Figure $3 \mathrm{e}$ ) were found to be more energetic, with long-term average WPDs of 20, 22, 24 and $22 \mathrm{~kW} / \mathrm{m}$, respectively.

\subsection{Spatial Distribution of the Monthly Average Wave Power}

Figure 10 displays maps of the spatial distribution of the mean WPD for each month in the waters surrounding Taiwan. The gridded WPD was also averaged over the 20 years from 1991 to 2010 for each month. October was characterized by the most abundant monthly mean WPD—approximately $35-40 \mathrm{~kW} / \mathrm{m}$ for the sea areas surrounding Green Island and Orchid Island and southeast of Orchid Island. South of the Hengchun Peninsula and north of the Penghu Islands, the highest monthly mean WPD of $40 \mathrm{~kW} / \mathrm{m}$ occurred in November. A weaker monthly average WPD in the range of $8 \mathrm{~kW} / \mathrm{m}-12 \mathrm{~kW} / \mathrm{m}$ was detected from April to June along the southern and southeastern offshore areas (Figure 10), 
and the least energetic months were May, June, July, and August for the Central Taiwan Strait, with a monthly mean WPD of only $2 \mathrm{~kW} / \mathrm{m}-7 \mathrm{~kW} / \mathrm{m}$ (Figure 10).
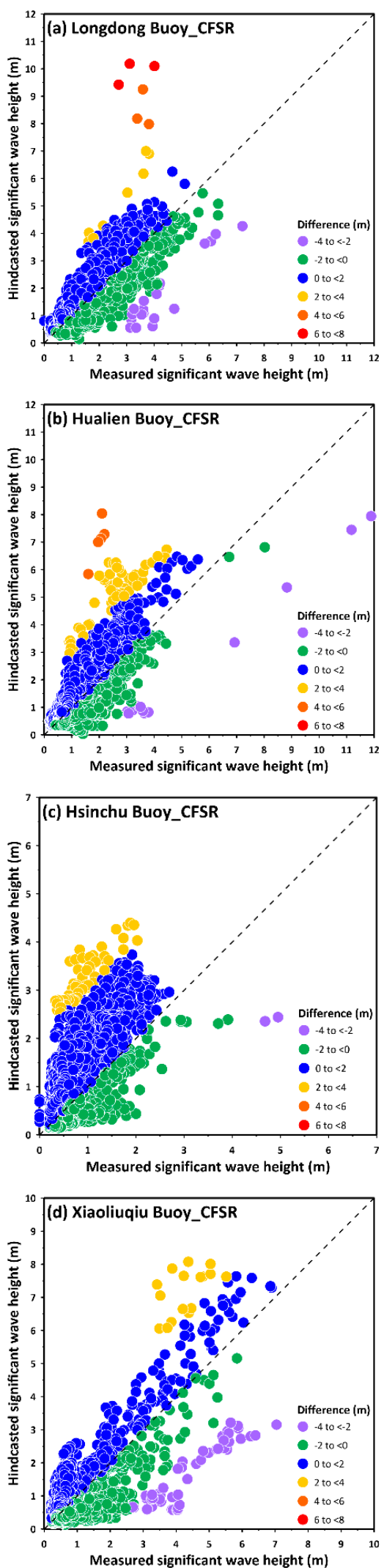
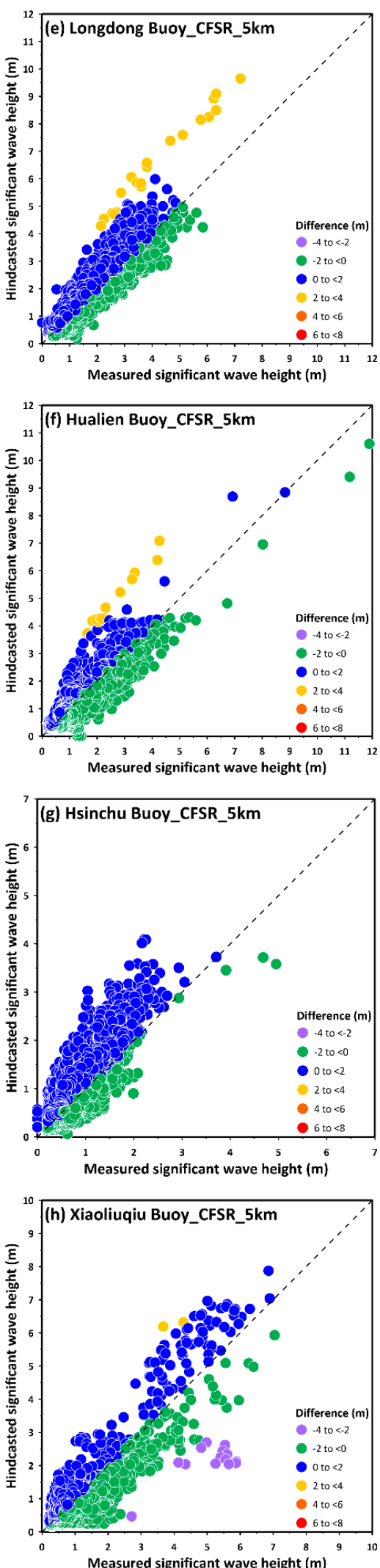

Figure 4. Scatter plots of the hindcasted versus measured significant wave heights (SWHs) for the (a,e) Longdong, $(\mathbf{b}, \mathbf{f})$ Hualien, $(\mathbf{c}, \mathbf{g})$ Hsinchu and $(\mathbf{d}, \mathbf{h})$ Xiaoliuqiu buoys using the (a-d) Climate Forecast System Reanalysis (CFSR) and (e-h) CFSR_5 km winds. 

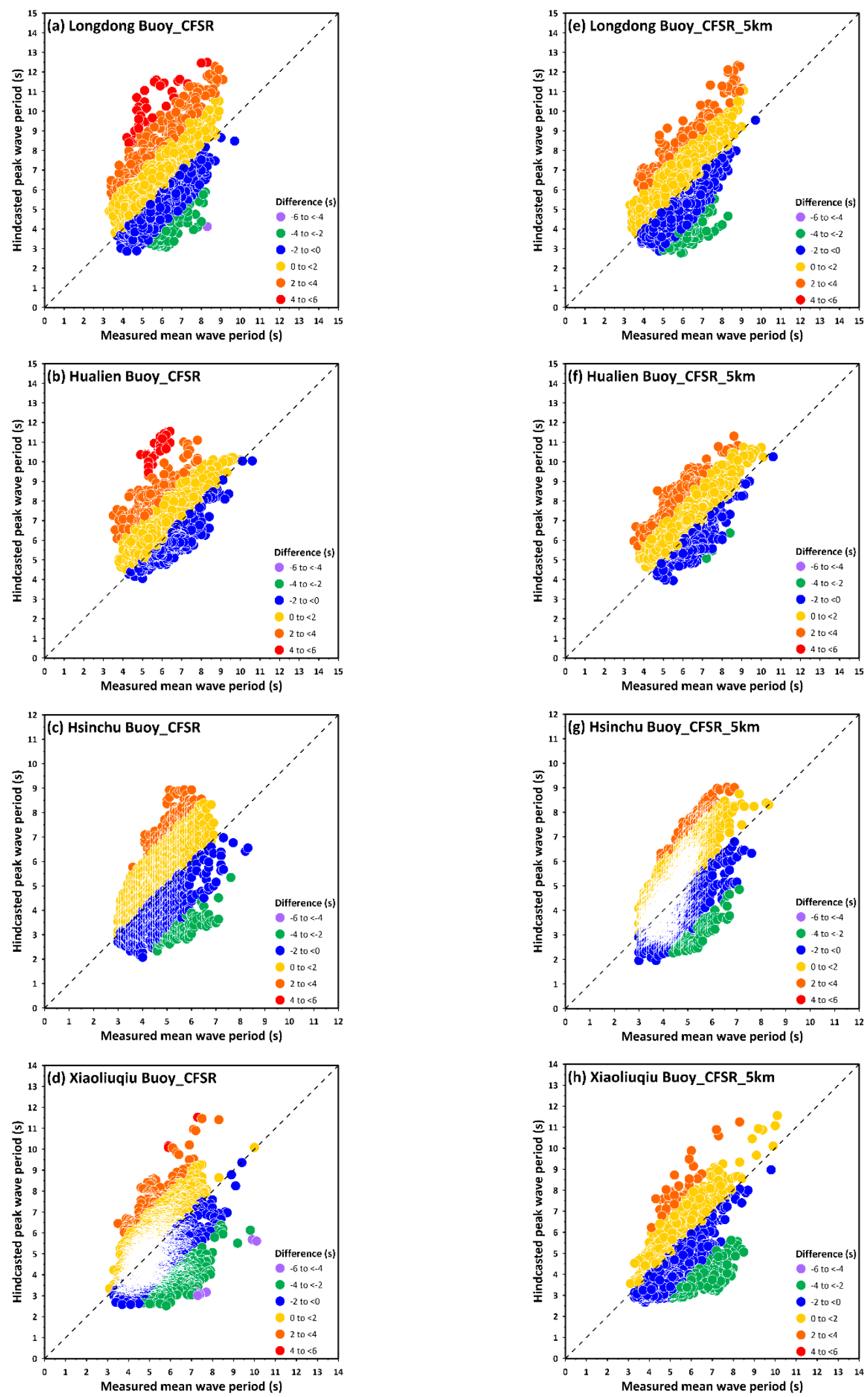

Figure 5. Scatter plots of the hindcasted versus measured peak wave periods for the (a,e) Longdong, (b,f) Hualien, $(\mathbf{c}, \mathbf{g})$ Hsinchu and $(\mathbf{d}, \mathbf{h})$ Xiaoliuqiu buoys using the (a-d) CFSR and (e-h) CFSR_5km winds. 

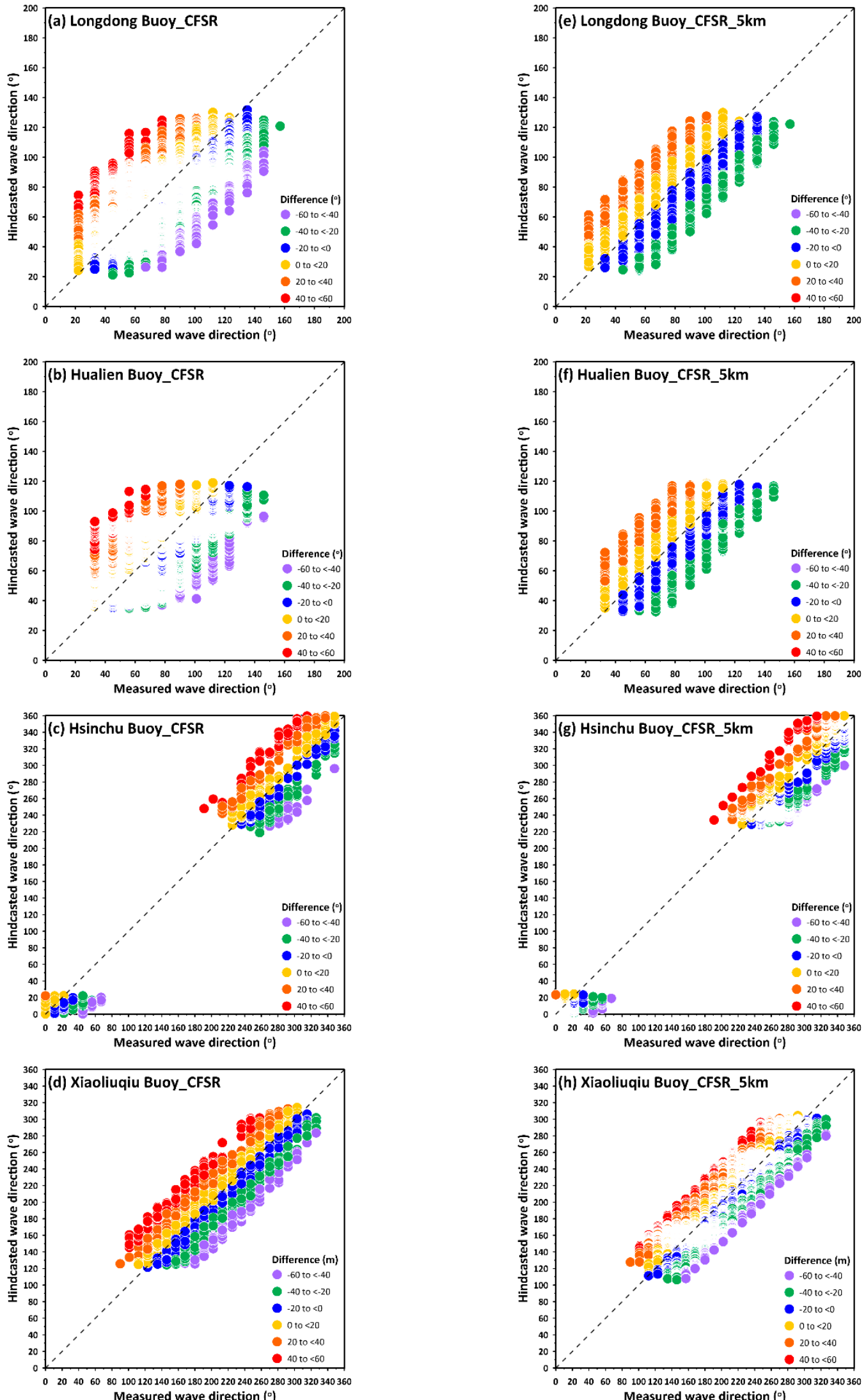

Figure 6. Scatter plots of the hindcasted versus measured wave directions for the (a,e) Longdong, (b,f) Hualien, (c,g) Hsinchu and $(\mathbf{d}, \mathbf{h})$ Xiaoliuqiu buoys using the (a-d) CFSR and (e-h) CFSR_5km winds. 
Table 1. Percentages of the model-data differences (units of meters) for the SWH at different classes and buoys using winds from CFSR (upper) and CFSR_5km (lower).

\begin{tabular}{cccccc}
\hline Buoy & {$[\mathbf{- 4 , - 2 )}$} & {$[\mathbf{- 2 , 0 )}$} & {$[\mathbf{0 , 2}$} & {$[\mathbf{2}, \mathbf{4})$} & {$[\mathbf{4 , 6 )}$} \\
\hline \multirow{2}{*}{ Longdong } & 0.23 & 28.96 & 70.65 & 0.99 & 0.03 \\
& 0.00 & 29.18 & 57.89 & 0.23 & 0.00 \\
\hline \multirow{2}{*}{ Hualien } & 0.14 & 31.76 & 67.34 & 0.71 & 0.06 \\
& 0.00 & 55.16 & 44.69 & 0.15 & 0.00 \\
\hline \multirow{2}{*}{ Hsinchu } & 0.02 & 20.50 & 78.80 & 0.68 & 0.00 \\
& 0.00 & 29.04 & 66.72 & 0.00 & 0.00 \\
\hline \multirow{2}{*}{ Xiaoliuqiu } & 0.56 & 43.45 & 55.80 & 0.18 & 0.00 \\
& 0.16 & 50.52 & 49.30 & 0.02 & 0.00 \\
\hline
\end{tabular}

Table 2. Percentages of the model-data differences (units of seconds) for the peak wave period at different classes and buoys using winds from CFSR (upper) and CFSR_5km (lower).

\begin{tabular}{cccccc}
\hline Buoy & {$[\mathbf{- 6 , - 4 )}$} & {$[\mathbf{- 4 , - 2 )}$} & {$[\mathbf{- 2 , 0 )}$} & {$[\mathbf{0 , 2}$} & {$[\mathbf{2 , 4 )}$} \\
\hline \multirow{2}{*}{ Longdong } & 0.01 & 1.10 & 38.71 & 57.20 & 3.14 \\
& 0.00 & 1.61 & 41.37 & 54.77 & 2.25 \\
\hline \multirow{2}{*}{ Hualien } & 0.00 & 0.00 & 17.60 & 76.28 & 5.85 \\
& 0.00 & 0.03 & 16.47 & 78.94 & 4.26 \\
\hline \multirow{2}{*}{ Hsinchu } & 0.00 & 1.30 & 35.65 & 61.37 & 1.68 \\
& 0.00 & 1.27 & 45.71 & 51.52 & 1.49 \\
\hline \multirow{2}{*}{ Xiaoliuqiu } & 0.08 & 3.38 & 64.06 & 31.27 & 1.18 \\
& 0.00 & 4.70 & 74.33 & 20.25 & 0.73 \\
\hline
\end{tabular}

Table 3. Percentages of the model-data differences (units of degree) for the wave direction at different classes and buoys using winds from CFSR (upper) and CFSR_5km (lower).

\begin{tabular}{cccccc}
\hline Buoy & {$[-\mathbf{6 0 ,}-\mathbf{4 0 )}$} & {$[-\mathbf{4 0 ,}-\mathbf{2 0})$} & {$[-\mathbf{2 0 , 0 )}$} & {$[\mathbf{0 , 2 0 )}$} & {$[\mathbf{2 0 , 4 0 )}$} \\
\hline \multirow{2}{*}{ Longdong } & 2.38 & 24.85 & 37.35 & 25.35 & 9.34 \\
& 0.00 & 26.37 & 39.27 & 26.35 & 8.01 \\
\hline \multirow{2}{*}{ Hualien } & 0.96 & 16.46 & 36.54 & 31.67 & 12.83 \\
& 0.00 & 19.33 & 37.08 & 31.56 & 12.03 \\
\hline \multirow{2}{*}{ Hsinchu } & 2.64 & 10.77 & 36.65 & 44.86 & 3.97 \\
& 2.28 & 9.36 & 37.56 & 46.22 & 3.66 \\
\hline \multirow{2}{*}{ Xiaoliuqiu } & 5.01 & 16.38 & 29.66 & 30.20 & 13.20 \\
& 4.91 & 16.89 & 33.21 & 29.64 & 12.33 \\
\hline
\end{tabular}

\subsection{Annual and Monthly Average Incidence for the Exploitable Wave Power}

Due to the purchase and deployment costs of wave energy converters, the sea area is worthy of exploitation only when the WPD exceeds $2 \mathrm{~kW} / \mathrm{m}$ [14,60-62]. To guarantee this requirement, only WPDs equal to or greater than $4 \mathrm{~kW} / \mathrm{m}$ were included in the calculation of the incidence of exploitable wave power. The spatial distribution of the incidence (in percentages) of the WPD exceeding $4 \mathrm{~kW} / \mathrm{m}$ in the offshore waters of Taiwan averaged over 1991 to 2010 is depicted in Figure 11. The highest incidences appear to be $70 \%-90 \%$ southeast of Taiwan, while the lowest incidence is only $30 \%$ in the nearshore southwestern waters off Taiwan. The sea area around the northern Penghu Islands exhibited a 50\% annual mean WPD incidence. Similarly, Figure 12 describes the monthly average incidence for the WPD exceeding $4 \mathrm{~kW} / \mathrm{m}$ in the waters surrounding Taiwan from 1991 to 2010. The monthly mean incidences along the eastern waters of Taiwan are approximately $100 \%$ in November, and they are always greater than $50 \%$ along the southeastern offshore areas 
every month. In July, the minimum monthly average incidence of $10 \%$ occurred in the Central Taiwan Strait; however, the monthly average incidences reached $80 \%$ in October, November, December, and January in the same sea area.
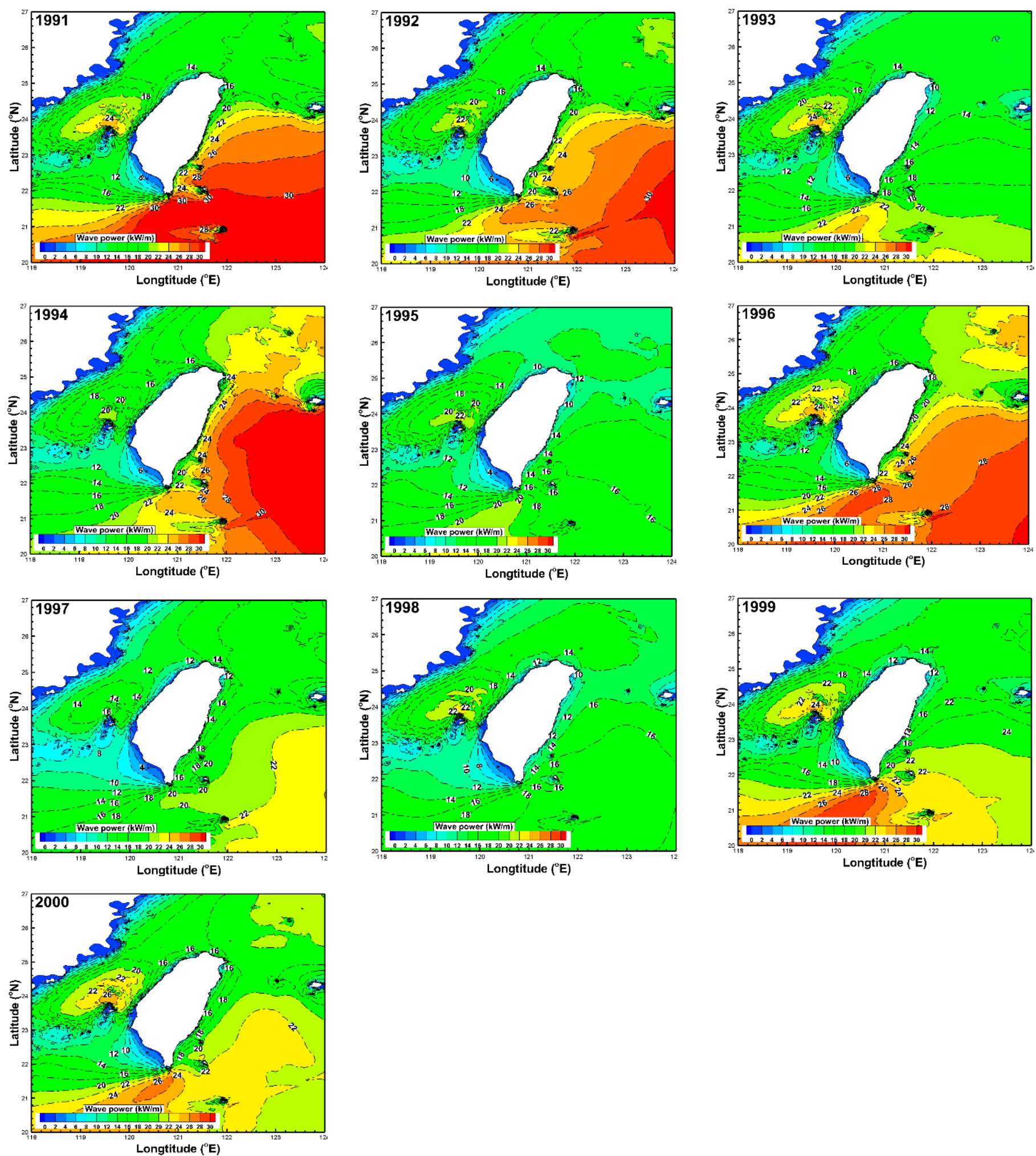

Figure 7. Spatial distributions of the annual average wave power in the offshore waters of Taiwan from 1991 to 2000. 

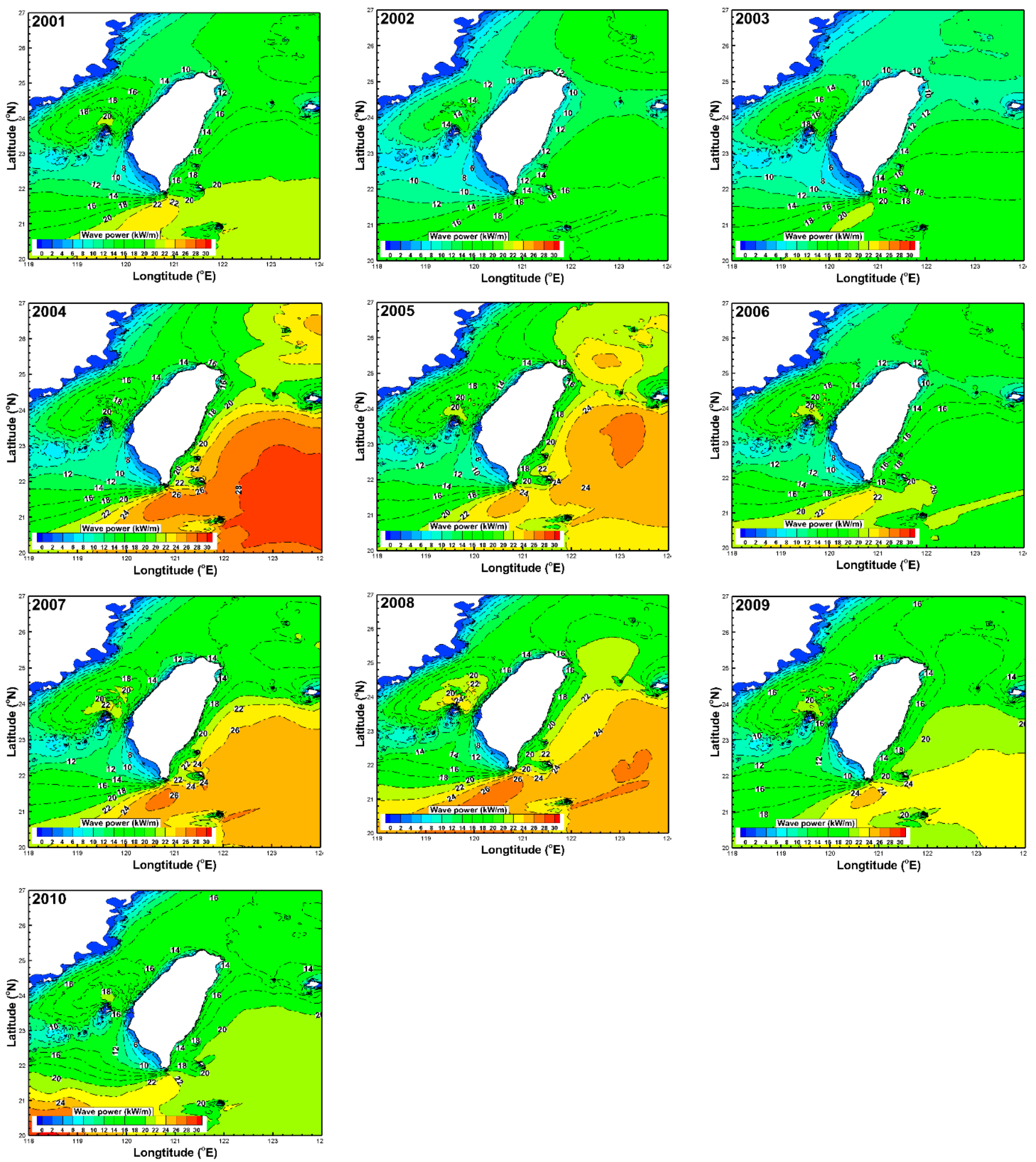

Figure 8. Spatial distributions of the annual average wave power in the offshore waters of Taiwan from 2001 to 2010. 


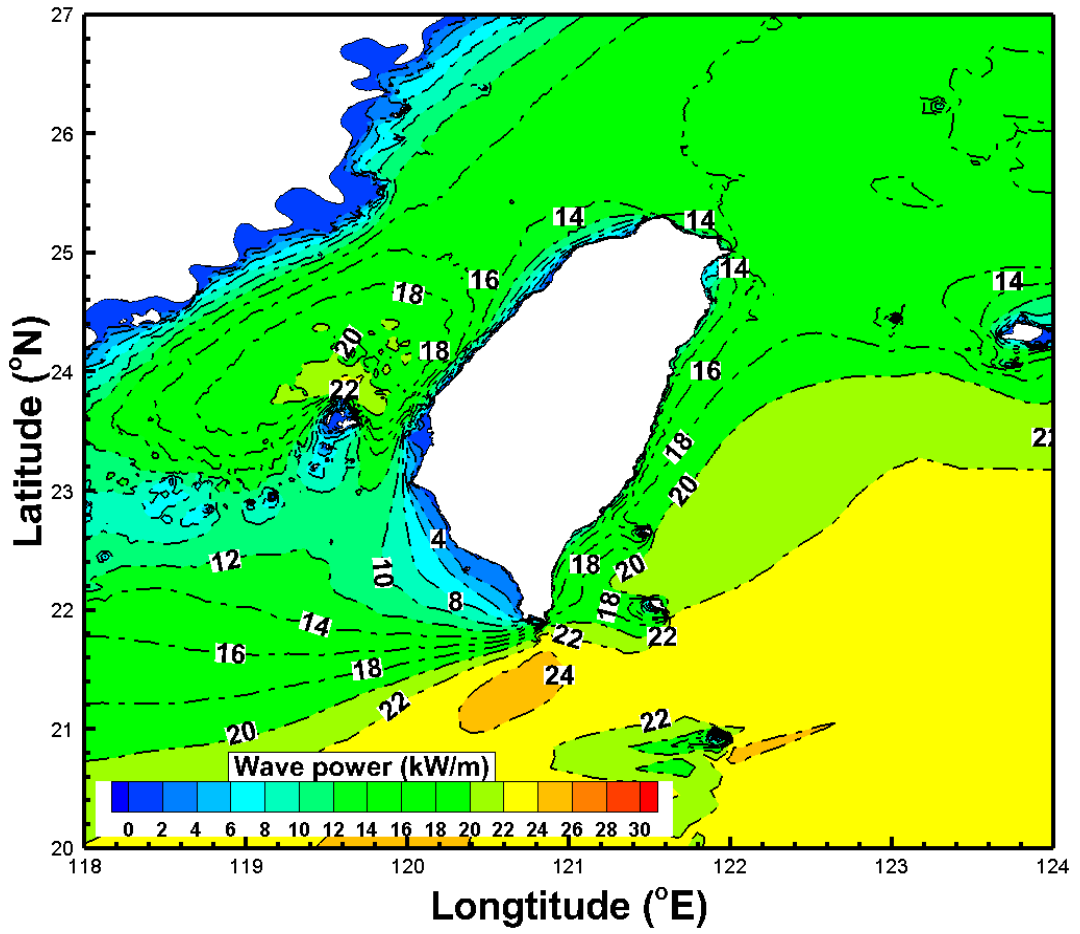

Figure 9. Spatial distribution of the wave power in the offshore waters of Taiwan averaged over 1991 to 2010 .
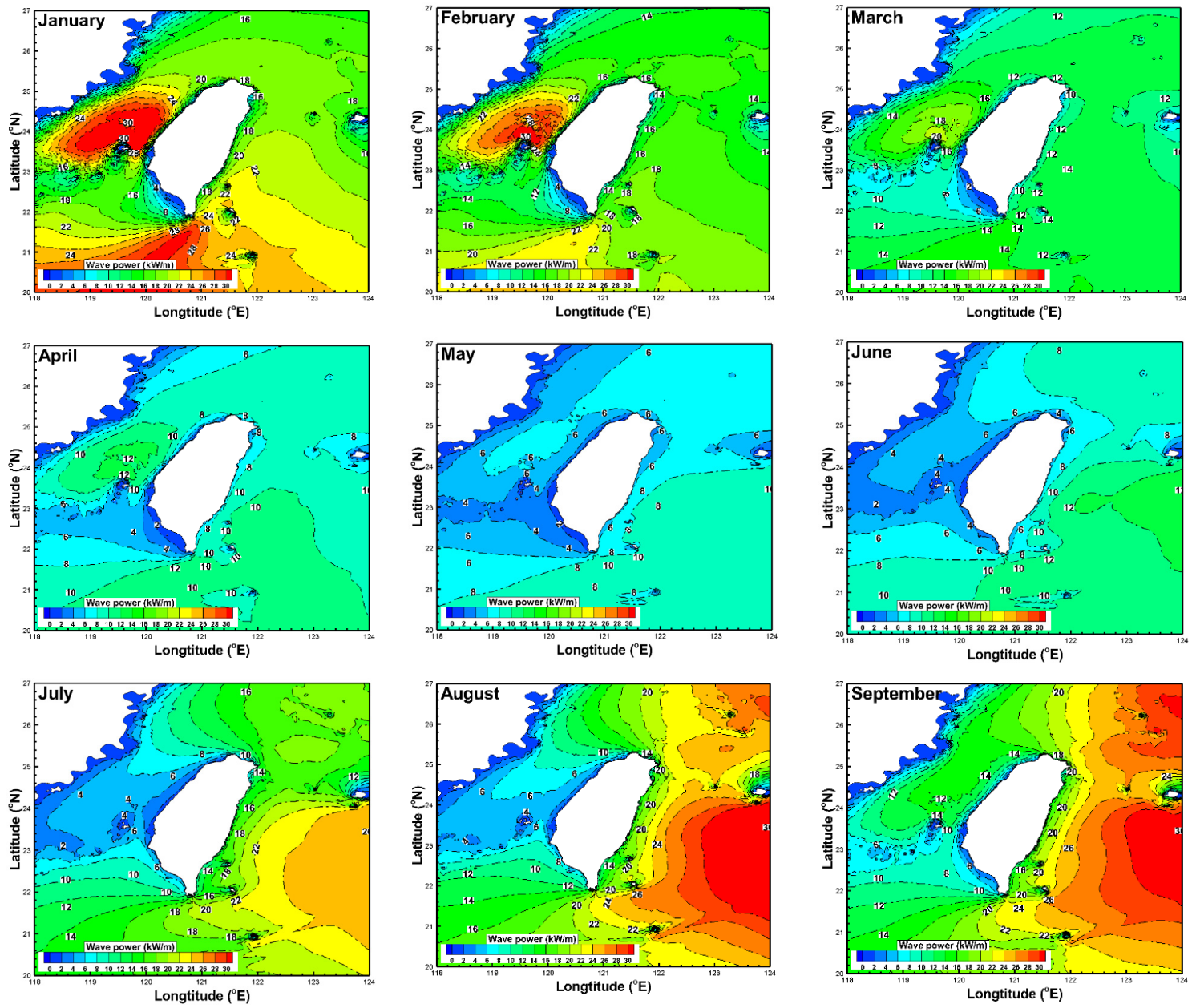

Figure 10. Cont. 

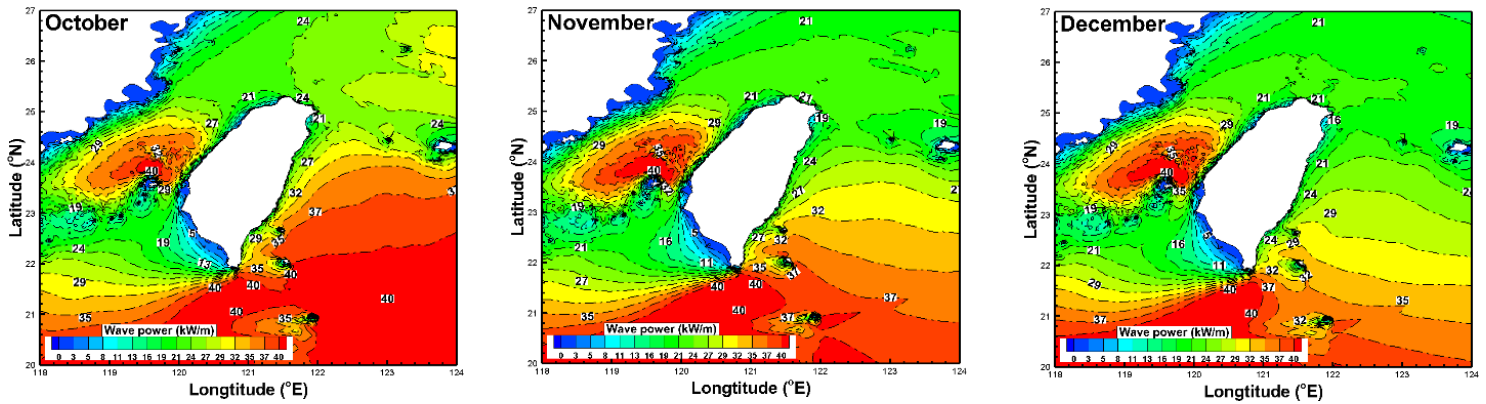

Figure 10. Spatial distributions of the monthly average wave power in the offshore waters of Taiwan from 1991 to 2010.

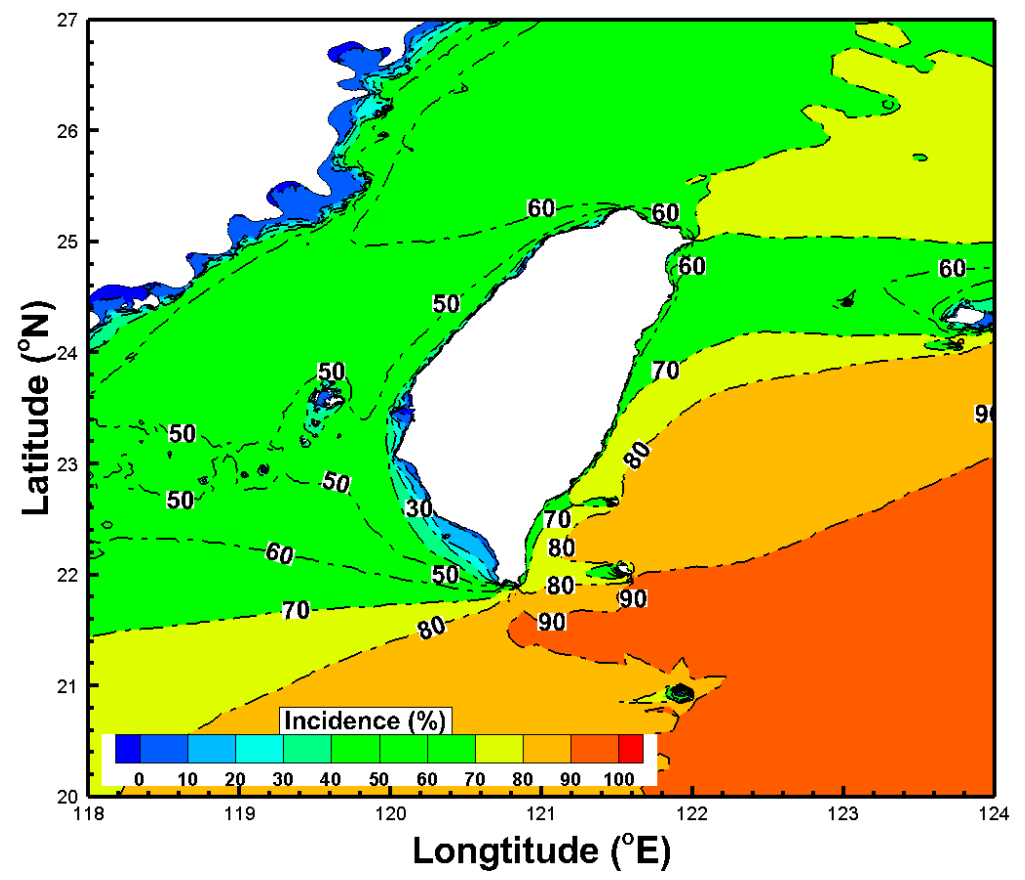

Figure 11. Spatial distribution of the incidence of the wave power exceeding $4 \mathrm{~kW} / \mathrm{m}$ in the offshore waters of Taiwan averaged over 1991 to 2010.
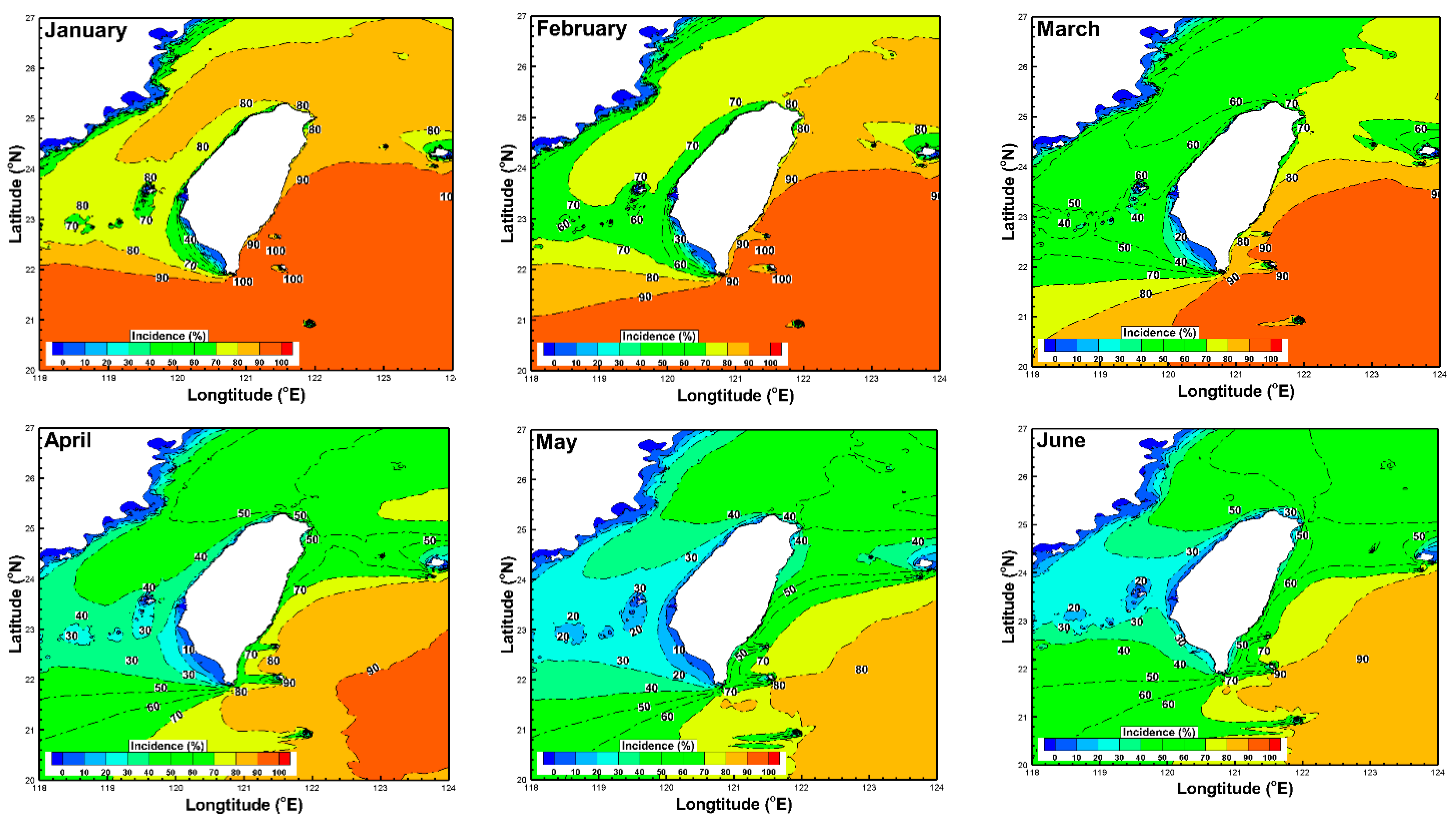

Figure 12. Cont. 

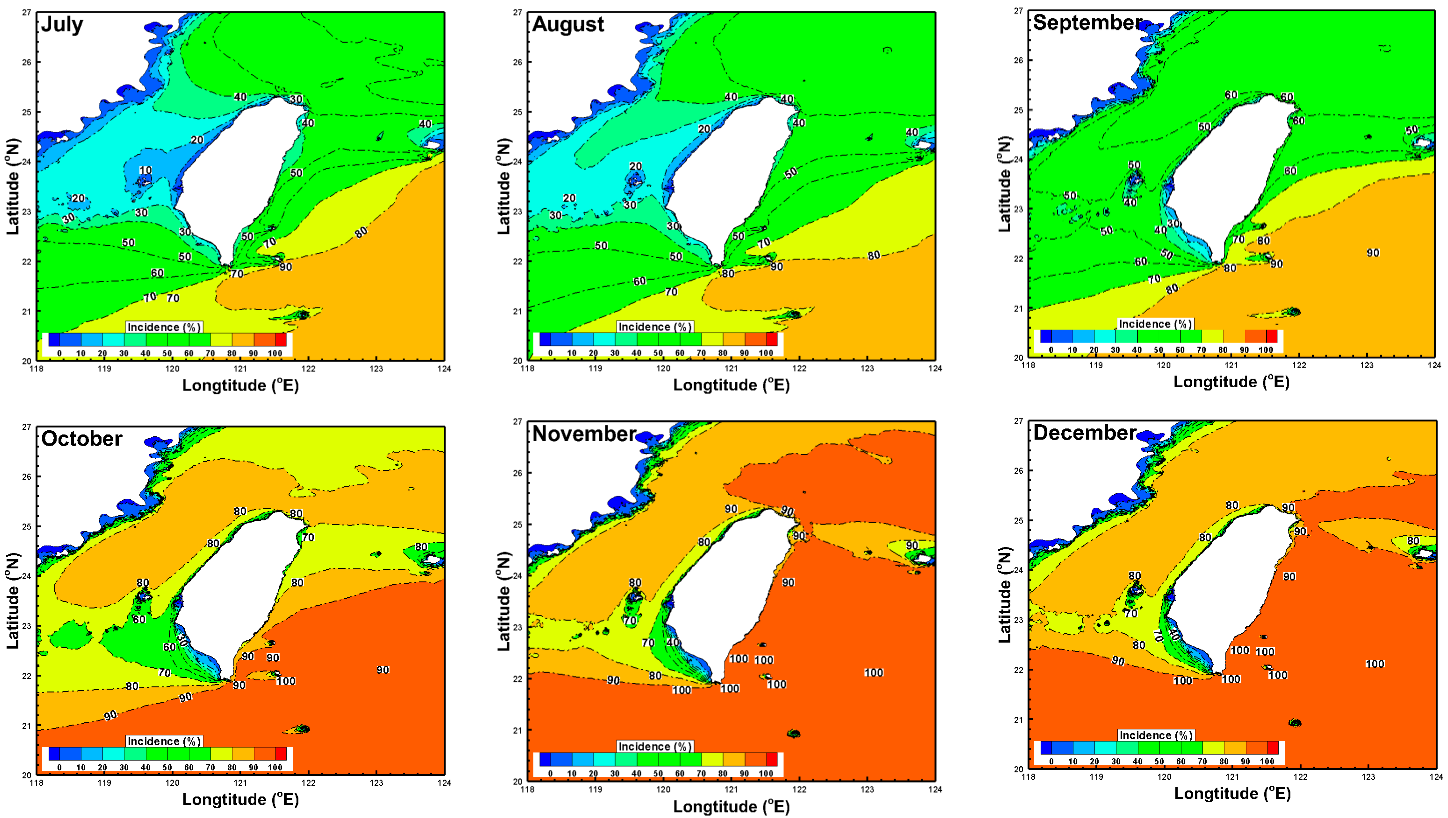

Figure 12. Spatial distributions of the monthly average incidence of the wave power exceeding $4 \mathrm{~kW} / \mathrm{m}$ in the offshore waters of Taiwan from 1991 to 2010.

\subsection{Variability of Wave Power}

Sea areas with a steady and constant WPD are more appropriate for the deployment of wave energy converters than WPD areas that are more energetic but unstable [63]. To evaluate the temporal variability of the WPD in the offshore waters of Taiwan, the MVI and COV were calculated via Equations (13) and (14), respectively. The offshore areas displayed a relatively low MVI, and the COV presented weaker temporal variability; therefore, these offshore areas are considered to be potential zones for installing wave energy converters $[64,65]$. The spatial distribution of the MVI for the WPD in the offshore waters of Taiwan averaged over 1991 to 2010 is depicted in Figure 13. The MVI ranges between 1.8 and 2.7; the maximum MVI is located near the northern Penghu Islands (in the Central Taiwan Strait), and the minimum MVI appears in the northwestern waters of Taiwan, while an MVI of 2.4 is found along the southern and southeastern Taiwanese waters. Figure 14 exhibits the spatial distribution of the COV for the WPD in the waters surrounding Taiwan averaged over 1991 to 2010. The highest and lowest COVs are 2.5 and 1.5 in the southwestern nearshore and northwestern offshore waters of Taiwan, respectively. Moreover, a COV of 2.0 is discovered in the Central Taiwan Strait and the southern and southwestern offshore areas of Taiwan.

\subsection{Determination of Optimal Wave Energy Hotspots}

The hotspots for deploying wave energy converters were determined according to the assessments of the annual mean WPD, incidence of the exploitable WPD, and MVI and COV of the WPD, as well as the distance between the coast and wave energy conversion devices. Four offshore regions located between Green Island and Orchid Island (hereafter $\mathrm{OH}_{-}$1, as shown in Figure 3b), southeast of Orchid Island (hereafter $\mathrm{OH} \_2$, as shown in Figure 3c), south of the Hengchun Peninsula (hereafter $\mathrm{OH}_{-} 3$, as shown in Figure 3d), and north of the Penghu Islands (hereafter $\mathrm{OH}_{-} 4$, as shown in Figure 3e) were considered the optimal hotspots for the deployment of wave energy converters. These areas are consistent with the spatial distributions of relatively high WPD and incidence but lower MVI and COV. The monthly mean, maximum and minimum WPDs averaged over 1991 to 2010 for OH_1, OH_2, OH_3 and OH_4 are illustrated in Figure 15. The monthly maximum WPD exceeded $90 \mathrm{~kW} / \mathrm{m}$ for OH_1, OH_2 and OH_3 in October and November and was approximately $100 \mathrm{~kW} / \mathrm{m}$ for OH_4 in November. The monthly average WPD reached 
30 kW/m-50 kW/m for OH_1, OH_2, OH_3 and OH_4 in October to December, while the monthly minimum WPD approached only $20 \mathrm{~kW} / \mathrm{m}$ for the four optimal hotspots in December. Furthermore, the long-term directional distributions of the WPD were analyzed because the wave direction is an important parameter for the placement of a wave energy converter $[35,66]$. Figure 16 presents rose diagrams of the WPD for each of the four optimal wave energy hotspots averaged over 1991 to 2010. The dominant WPD directions lie between the east and northeast for $\mathrm{OH} \_1, \mathrm{OH} 22$ and $\mathrm{OH}$ _3; however, the northeast is the prevailing WPD direction within $\mathrm{OH} \_4$. The characteristics of the selected optimal wave energy hotspots, such as the coordinates and water depths, are listed in Table 4.

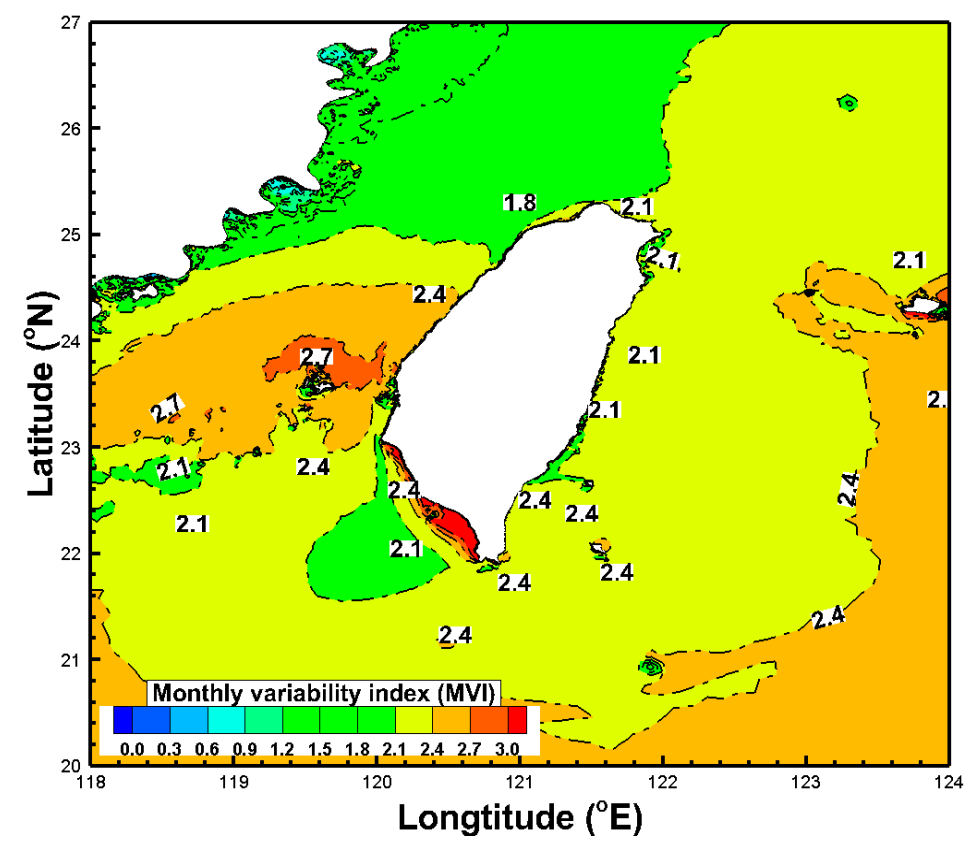

Figure 13. Spatial distribution of the monthly variability index (MVI) of wave power in the offshore waters of Taiwan averaged over 1991 to 2010.

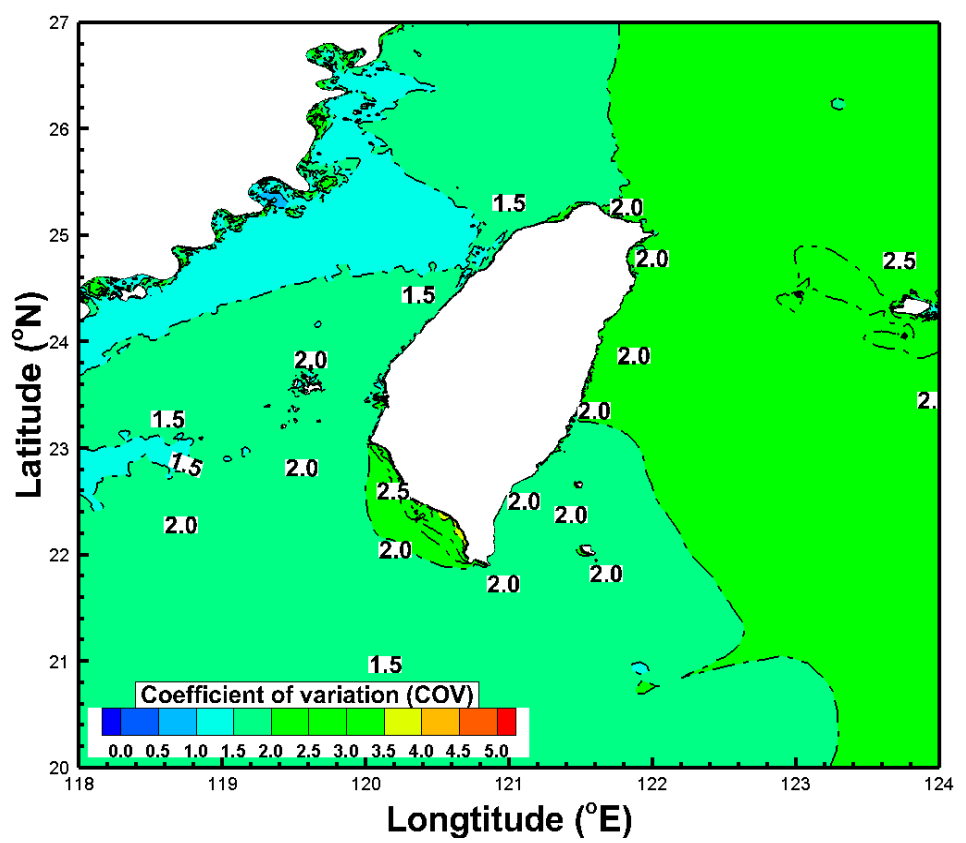

Figure 14. Spatial distribution of the coefficient of variation (COV) of wave power in the offshore waters of Taiwan averaged over 1991 to 2010. 

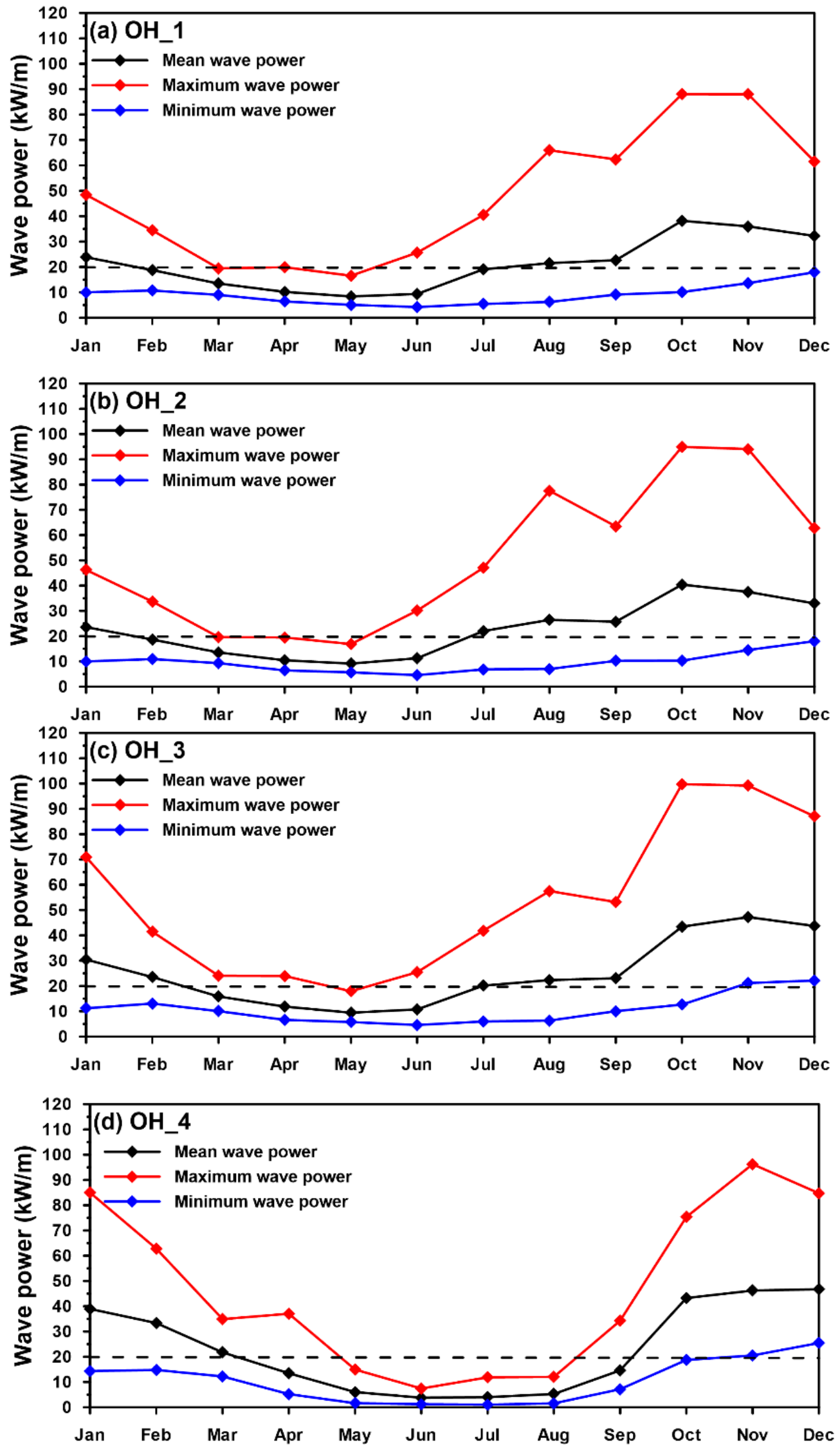

Figure 15. Monthly mean, maximum and minimum wave powers from 1991 to 2010 for four optimal wave energy hotspots: (a) $\mathrm{OH} \_1$, (b) $\mathrm{OH} \_2$, (c) $\mathrm{OH} \_3$, and (d) $\mathrm{OH} \_4$. 

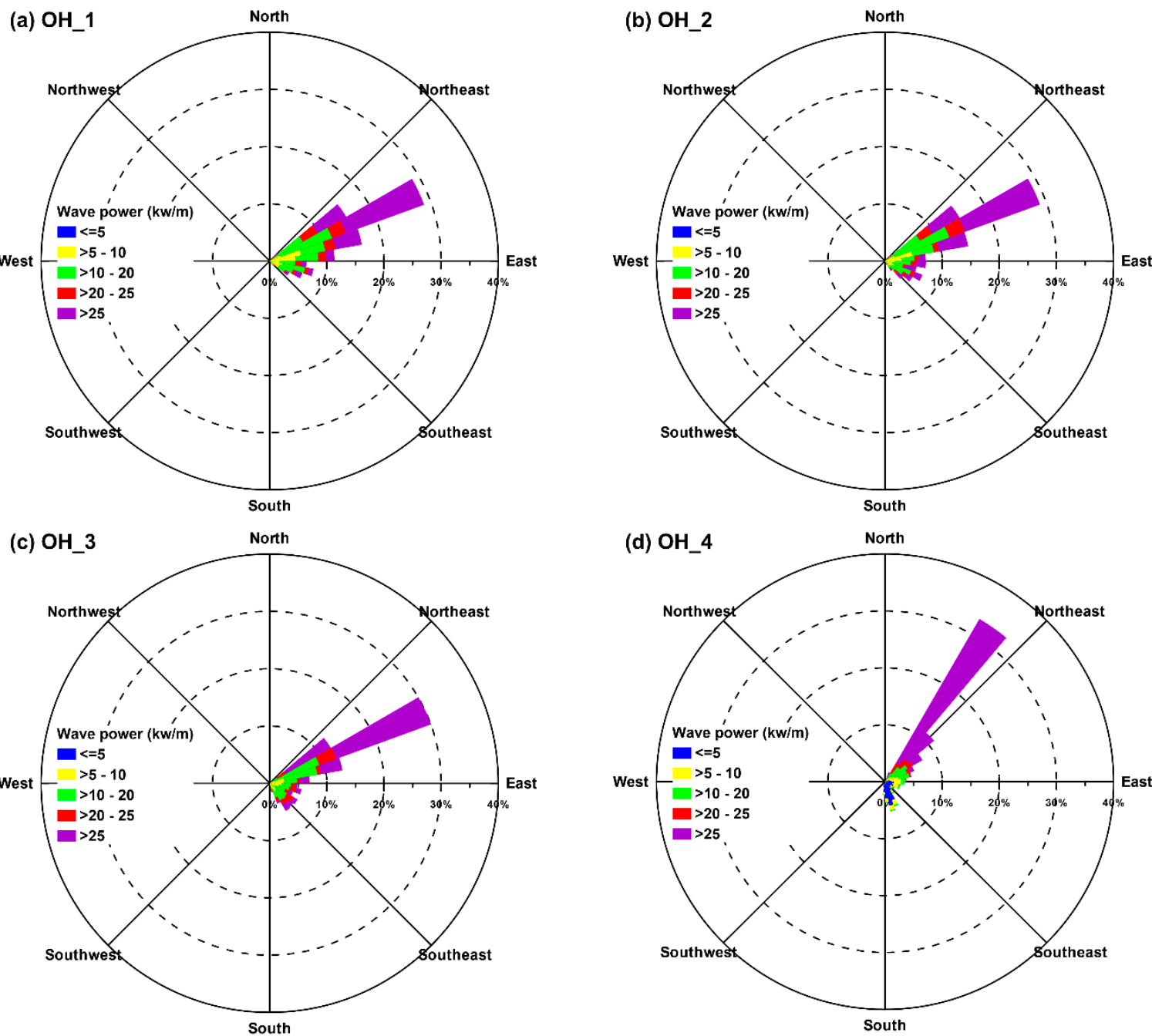

Figure 16. Directional distributions of the wave power averaged over 1991 to 2010 for four optimal wave energy hotspots: (a) $\mathrm{OH} \_1,(\mathbf{b}) \mathrm{OH} \_$, (c) $\mathrm{OH} \_3$ and (d) $\mathrm{OH} \_4$.

Table 4. Characteristics of the selected optimal wave energy hotspots.

\begin{tabular}{ccccc}
\hline \multirow{2}{*}{ Buoy } & \multicolumn{3}{c}{ Optimum Hotspots for the Deployment of Wave Energy Converters } \\
\cline { 2 - 5 } & OH_1 & OH_2 & OH_3 & OH_4 \\
\hline Lat. $\left(^{\circ}\right)$, Lon. $\left(^{\circ}\right)$ & $(121.48,22.34)$ & $(121.65,21.89)$ & $(120.77,21.49)$ & $(119.64,23.94)$ \\
$W a t e r$ depth $(\mathrm{m})$ & -1268 & -1360 & -427 & -71 \\
$W P_{m}(\mathrm{~kW} / \mathrm{m})$ & 21.03 & 22.62 & 24.91 & 22.33 \\
$W E_{t}(\mathrm{MWh} / \mathrm{m})$ & 184.22 & 198.15 & 218.21 & 195.61 \\
$W E_{e}(\mathrm{MWh} / \mathrm{m})$ & 158.06 & 182.89 & 196.39 & 101.33 \\
\hline "” $^{\prime}$ is the symbol for water depth below mean sea level; $W P_{m}$ is the annual mean wave power; annual total wave
\end{tabular}
energy outputs; $W E_{t}$ is the annual total wave energy outputs; $W E_{e}$ is the exploitable annual wave energy output.

\section{Discussion}

The wave power is weak from March to June for $\mathrm{OH} \_1, \mathrm{OH} \_2$ and $\mathrm{OH} \_3$ and from April to August for $\mathrm{OH} \_4$, while the wave power is stronger from October to February for all four optimal hotspots. Additionally, the prevailing WPD directions for all optimal hotspots are nearly northeast. This phenomenon might be attributable to the prevalence of the northeast monsoon during late September to early May in Taiwan $[67,68]$. Alternatively, the long-term statistical data (from 1991 to 2019) issued by the CWB reveal that July, August, 
and September constitute the typhoon season in Taiwan; however, higher WPDs occur outside of the typhoon season. Although large waves are indeed induced by typhoons, the wave power in the offshore waters of Taiwan is driven mainly by the strong northeast monsoon. Moreover, the deeper water bathymetry also contributes to an increase in the WPD at these hotspots.

By applying Equation (12) with a given $\Delta t_{i}$ equal to $8760 \mathrm{~h}$, the annual total wave energy outputs $\left(W E_{t}\right)$ for the four optimal hotspots were calculated, and the results are summarized in Table 4. $W E_{t}$ values of $184.22,198.15,218.21$, and $195.61 \mathrm{MWh} / \mathrm{m}$ were estimated for $\mathrm{OH} \_1, \mathrm{OH} \_2, \mathrm{OH}$ 3, and $\mathrm{OH} \_4$, respectively, which are more than double the results of a previous study in the same offshore waters $[35,57]$. The reason for such underestimated values is that the previous studies used wind field data with a temporal resolution of $6 \mathrm{~h}$ and a spatial resolution of $0.125^{\circ}$ from the ERA-Interim dataset, and the ERA-Interim global reanalysis is inferior to a regional high-resolution dynamical scaling atmospheric model in the performance of wind speeds. This is particularly true under severe weather conditions, e.g., strong monsoons or typhoons. In other words, the wave energy resources and the optimal hotspots for wave energy evaluated in the present study are more reliable than the results from previous studies $[35,57]$. The exploitable annual wave energy outputs $\left(W E_{e}\right)$ for the hotspots were also assessed, where only $\Delta t_{i}$ was replaced by the total hours corresponding to the WPD equal to or greater than $4 \mathrm{~kW} / \mathrm{m}$, i.e., $8760 \mathrm{~h}$ multiplied by an annual mean incidence. The estimations of $W E_{e}$ for OH_1,OH_2,OH_3, and OH_4 are 158.06, 182.89, 196.39, and 101.33 MWh/m, respectively (as listed in Table 4).

\section{Summary and Conclusions}

A three-layer nested Weather Research and Forecast (WRF) model with $45 \mathrm{~km}, 15 \mathrm{~km}$ and $5 \mathrm{~km}$ spatial resolutions for Domain 1, Domain 2, and Domain 3, respectively, was implemented over Taiwan and its offshore islands. The high-resolution WRF model was used to downscale the Climate Forecast System Reanalysis (CFSR) product dynamically. The hourly winds $10 \mathrm{~m}$ above sea level derived from the WRF model (CFSR_5km) and extracted from CFSR during the period of 2010 served as the meteorological boundary conditions for SCHISM-WWM-III, a fully coupled wave-circulation model. The validation results revealed that the hindcasting performance of SCHISM-WWM-III for the wave parameters, such as significant wave height (SWH), peak wave period and wave direction, by employing the winds from CFSR_5km was superior to those adopting the CFSR wind field. Therefore, the long-term sea states covering the period from 1991 to 2010 were hindcasted through the combination of CFSR_5km winds with SCHISM-WWM-III for assessing the offshore wave energy resources in Taiwan. The spatial distribution of the annual wave power density (WPD) averaged over twenty years shows that the offshore areas between Green Island and Orchid Island (OH_1), southeast of Orchid Island (OH_2), south of the Hengchun Peninsula (OH_3), and north of the Penghu Islands (OH_4) are more energetic than other regions, with long-term annual average WPDs of 20, 22, 24 and $22 \mathrm{~kW} / \mathrm{m}$, respectively. An analysis of the monthly mean WPDs over twenty years showed that the greatest WPD is observed from October to January, which means that the wave power is driven mainly by the northeast monsoon in the surrounding waters of Taiwan, even though typhoons can induce extreme waves. The annual average WPD, incidence of the hourly WPD greater than or equal to $4 \mathrm{~kW} / \mathrm{m}$, monthly variability index (MVI) and coefficient of variation (COV) for the WPD indicate that sea areas OH_1, OH_2, $\mathrm{OH} \_3$ and $\mathrm{OH} \_4$ can be considered appropriate sites for deploying wave energy converters. The exploitable long-term annual average total wave energy outputs are estimated to be $158.06,182.89,196.39$, and 101.33 MWh/m for hotspots OH_1,OH_2,OH_3, and OH_4, respectively. Additionally, northeast is the primary wave direction for each of the four hotspots. The approach proposed by the present study could be applied elsewhere in the world, especially for a regional-scale study of wave power resources. As for evaluating the global wave energy resources, the reanalysis product is sufficient to reflect the distribution of wave energy worldwide. 
Author Contributions: Conceptualization, C.-T.C., S.-C.H., T.-Y.C., W.-B.C., H.-L.W., J.-H.J. and L.Y.L.; methodology, W.-B.C. and C.-T.C.; validation, W.-B.C.; formal analysis, T.-Y.C., C.-T.C., H.-L.W. and J.-H.J.; writing-original draft preparation, W.-B.C. and S.-C.H.; supervision, S.-C.H., and L.-Y.L. All authors have read and agreed to the published version of the manuscript.

Funding: This research was supported by the Ministry of Science and Technology (MOST), Taiwan, grant No. MOST 109-2221-E-865-001.

Institutional Review Board Statement: Not applicable.

Informed Consent Statement: Not applicable.

Data Availability Statement: Publicly available datasets were analyzed in the present study. The data can be found here: https://ocean.cwb.gov.tw/V2/data_interface/datasets.

Acknowledgments: The authors thank the Central Weather Bureau and Department of Land Administration, Ministry of the Interior of Taiwan, for providing the measured data, as well as Joseph Zhang at the Virginia Institute of Marine Science, College of William \& Mary, and Aron Roland at the BGS IT\&E GmbH, Darmstadt, Germany, for kindly sharing their experiences concerning the use of the numerical model.

Conflicts of Interest: The authors declare no conflict of interest.

\section{References}

1. Doyle, S.; Aggidis, G.A. Development of multi-oscillating water columns as wave energy converters. Renew. Sustain. Energy Rev. 2019, 107, 75-86. [CrossRef]

2. Cruz, J. Ocean Wave Energy - Current Status and Future Prospects; Springer AG: Cham, Switzerland, 2008.

3. Aderinto, T.; Li, H. Ocean Wave Energy Converters: Status and Challenges. Energies 2018, 11, 1250. [CrossRef]

4. Gunn, K.; Stock-Williams, C. Quantifying the global wave power resource. Renew. Energy 2012, 44, 296-304. [CrossRef]

5. Pérez-Collazo, C.; Greaves, D.; Iglesias, G. A review of combined wave and offshore wind energy. Renew. Sustain. Energy Rev. 2015, 42, 141-153. [CrossRef]

6. Neill, S.P.; Vogler, A.; Goward-Brown, A.J.; Baston, S.; Lewis, M.J.; Gillibrand, P.A.; Waldman, S.; Woolf, D.K. The wave and tidal resource of Scotland. Renew. Energy 2017, 114, 3-17.

7. Fairley, I.; Lewis, M.; Robertson, B.; Hermer, M.; Masters, I.; Horrillo-Caraballo, J.; Karunarathna, H.; Reeve, D.E. A classification system for global wave energy resources based on multivariate clustering. Appl. Energy 2020, 262, 114515. [CrossRef]

8. Arinaga, R.A.; Cheung, K.F. Atlas of global wave energy from 10 years of reanalysis and hindcast data. Renew. Energy 2012, 39, 49-64. [CrossRef]

9. Reguero, B.G.; Losada, I.J.; Mendez, F.J. A global wave power resource and its seasonal, interannual and long-term variability. Appl. Energy 2015, 148, 366-380. [CrossRef]

10. Zhou, G.; Huang, J.; Zhang, G. Elevation of the wave energy conditions along the coastal waters of Beibu Gulf, China. Energy 2015, 85, 449-457. [CrossRef]

11. Bento, R.A.; Martinho, P.; Soares, C.G. Numerical modelling of the wave energy in Galway Bay. Renew. Energy 2015, 78, 457-466. [CrossRef]

12. Mirzaei, A.; Tangang, F.; Juneng, L. Wave energy potential assessment in the central and southern regions of the South China Sea. Renew. Energy 2015, 80, 454-470.

13. Akpmar, A.; Bingolbali, B.; Van Vledder, G.P. Long-term analysis of wave power potential in the Black Sea, Based on 31-year SWAN simulations. Ocean. Eng. 2017, 13, 482-497. [CrossRef]

14. Lin, Y.; Dong, S.; Wang, Z.; Guedes Soares, G. Wave energy assessment in the China adjacent seas on the basis of a 20-year SWAN simulation with unstructured grids. Renew. Energy 2019, 136, 275-295. [CrossRef]

15. Yang, Z.; García-Medina, G.; Wu, W.-C.; Wang, T. Characteristics and variability of the nearshore wave resource on the U.S. West Coast. Energy 2020, 203, 117818. [CrossRef]

16. Gonçalves, M.; Martinho, P.; Soares, C.G. Assessment of wave energy in the Canary Islands. Renew. Energy 2013, 68, 774-784. [CrossRef]

17. Inquiry System for Energy Statistical Data, Taiwan. Available online: https://www.moeaboe.gov.tw/wesnq/Views/B01/ wFrmB0102.aspx (accessed on 20 January 2021).

18. Saha, S.; Moorthi, S.; Pan, H.-L.; Wu, X.; Wang, J.; Nadiga, S.; Tripp, P.; Kistler, R.; Woollen, J.; Behringer, D.; et al. The NCEP Climate Forecast System Reanalysis. Bull. Amer. Meteorol. Soc. 2010, 91, 1015-1057. [CrossRef]

19. Skamarock, W.C.; Klemp, J.B.; Dudhia, J.; Gill, D.O.; Barker, D.M.; Duda, M.G.; Huang, X.Y.; Wang, W.; Powers, J.G. A Description of the Advanced Research WRF Version 3; NCAR Technical Note; NCAR/TN-475 + STR; Mesoscale and Microscale Meteorology Division, National Center for Atmospheric Research: Boulder, CO, USA, 2008.

20. Routray, A.; Mohanty, U.; Niyogi, D.; Rizvi, S.; Osuri, K.K. Simulation of heavy rainfall events over Indian monsoon region using WRF-3DVAR data assimilation system. Meteorol. Atmos. Phys. 2010, 106, 107-125. [CrossRef] 
21. Mohanty, U.; Routray, A.; Osuri, K.K.; Prasad, S.K. A study on simulation of heavy rainfall events over Indian region with ARW-3DVAR modeling system. Pure Appl. Geophys. 2012, 169, 381-399. [CrossRef]

22. Routray, A.; Mohanty, U.; Osuri, K.K.; Kar, S.; Niyogi, D. Impact of satellite radiance data on simulations of Bay of Bengal tropical cyclones using the WRF-3DVAR modeling system. IEEE Trans. Geosci. Remote Sens. 2016, 54, 2285-2303. [CrossRef]

23. Osuri, K.K.; Nadimpalli, R.; Mohanty, U.C.; Niyogi, D. Prediction of rapid intensification of tropical cyclone Phailin over the Bay of Bengal using the HWRF modelling system. Q. J. R. Meteorol. Soc. 2017, 143, 678-690. [CrossRef]

24. Madala, S.; Satyanarayana, A.; Rao, T.N. Performance evaluation of PBL and cumulus parameterization schemes of WRF ARW model in simulating severe thunderstorm events over Gadanki MST radar facility-case study. Atmos. Res. 2014, 139, 1-17. [CrossRef]

25. Osuri, K.; Nadimpalli, R.; Mohanty, U.; Chen, F.; Rajeevan, M.; Niyogi, D. Improved prediction of severe thunderstorms over the Indian Monsoon region using high-resolution soil moisture and temperature initialization. Sci. Rep. 2017, 7, 41377. [CrossRef] [PubMed]

26. Powers, J.G.; Klemp, J.B.; Skamarock, W.C.; Davis, C.A.; Dudhia, J.; Gill, D.O.; Coen, J.L.; Gochis, D.J. The Weather Research and Forecasting Model: Overview, system efforts, and future directions. Bull. Am. Meteorol. Soc. 2017, 98, 1717-1737. [CrossRef]

27. Zhang, Y.J.; Ye, F.; Stanev, E.V.; Grashorn, S. Seamless cross-scale modelling with SCHISM. Ocean. Model. 2016, 102, 64-81. [CrossRef]

28. Zhang, Y.J.; Baptista, A.M. SELFE: A semi-implicit Eulerian-Lagrangian finite-element model for cross-scale ocean circulation. Ocean. Model. 2008, 21, 71-96. [CrossRef]

29. Shchepetkin, A.F.; McWilliams, J.C. The regional oceanic modeling system (ROMS): A split-explicit, free-surface, topographyfollowing-coordinate, oceanic model. Ocean. Model. 2005, 9, 347-404. [CrossRef]

30. Chen, W.-B.; Liu, W.-C. Investigating the fate and transport of fecal coliform contamination in a tidal estuarine system using a three-dimensional model. Marine Pollut. Bull. 2017, 116, 365-384. [CrossRef]

31. Chen, W.-B.; Liu, W.-C. Modeling flood inundation Induced by river flow and storm surges over a river basin. Water 2014, 6, 3182-3199. [CrossRef]

32. Chen, W.-B.; Liu, W.-C. Assessment of storm surge inundation and potential hazard maps for the southern coast of Taiwan. Nat. Hazards 2016, 82, 591-616. [CrossRef]

33. Chen, Y.-M.; Liu, C.-H.; Shih, H.-J.; Chang, C.-H.; Chen, W.-B.; Yu, Y.-C.; Su, W.-R.; Lin, L.-Y. An Operational Forecasting System for Flash Floods in Mountainous Areas in Taiwan. Water 2019, 11, 2100. [CrossRef]

34. Chen, W.-B.; Chen, H.; Lin, L.-Y.; Yu, Y.-C. Tidal Current Power Resource and Influence of Sea-Level Rise in the Coastal Waters of Kinmen Island, Taiwan. Energies 2017, 10, 652. [CrossRef]

35. Shih, H.-J.; Chang, C.-H.; Chen, W.-B.; Lin, L.-Y. Identifying the Optimal Offshore Areas for Wave Energy Converter Deployments in Taiwanese Waters Based on 12-Year Model Hindcasts. Energies 2018, 11, 499. [CrossRef]

36. Shih, H.-J.; Chen, H.; Liang, T.-Y.; Fu, H.-S.; Chang, C.-H.; Chen, W.-B.; Su, W.-R.; Lin, L.-Y. Generating potential risk maps for typhoon-induced waves along the coast of Taiwan. Ocean. Eng. 2018, 163, 1-14. [CrossRef]

37. Chen, W.-B.; Chen, H.; Hsiao, S.-C.; Chang, C.-H.; Lin, L.-Y. Wind forcing effect on hindcasting of typhoon-driven extreme waves. Ocean. Eng. 2019, 188, 106260. [CrossRef]

38. Hsiao, S.-C.; Chen, H.; Chen, W.-B.; Chang, C.-H.; Lin, L.-Y. Quantifying the contribution of nonlinear interactions to storm tide simulations during a super typhoon event. Ocean. Eng. 2019, 194, 106661. [CrossRef]

39. Komen, G.J.; Cavaleri, L.; Donelan, M.; Hasselmann, K.; Hasselmann, S.; Janssen, P.A.E.M. Dynamics and Modelling of Ocean Waves; Cambridge University Press: Cambridge, UK, 1994.

40. Hsu, T.W.; Ou, S.-H.; Liau, J.-M. Hindcasting nearshore wind waves using a FEM code for SWAN. Coast. Eng. 2005, 52, 177-195. [CrossRef]

41. Roland, A. Development of WWM II: Spectral Wave Modeling on Unstructured Meshes. Ph.D. Thesis, Technology University Darmstadt, Darmstadt, Germany, 2009.

42. Yanenko, N.N. The Method of Fractional Steps; Springer: Berlin/Hamburg, Germany, 1971.

43. Leonard, B.P. The ultimate conservative difference scheme applied to unsteady one-dimensional advection. Comput. Method. Appl. Mech. 1991, 88, 17-74. [CrossRef]

44. Hasselmann, K.; Barnett, T.P.; Bouws, E.; Carlson, H.; Cartwright, D.E.; Enke, K.; Ewing, J.A.; Gienapp, H.; Hasselmann, D.E.; Kruseman, P.; et al. Measurements of Wind-Wave Growth and Swell Decay during the Joint North. Sea Wave Project (JONSWAP); Deutsches Hydrographisches Institut: Berlin/Hamburg, Germany, 1973.

45. Roland, A.; Zhang, Y.J.; Wang, H.V.; Meng, Y.; Teng, Y.-C.; Maderich, V.; Brovchenko, I.; Dutour-Sikiric, M.; Zanke, U. A fully coupled 3D wave-current interaction model on unstructured grids. J. Geophys. Res. 2012, 117, C00J33. [CrossRef]

46. Hsiao, S.-C.; Chen, H.; Wu, H.-L.; Chen, W.-B.; Chang, C.-H.; Guo, W.-D.; Chen, Y.-M.; Lin, L.-Y. Numerical Simulation of Large Wave Heights from Super Typhoon Nepartak (2016) in the Eastern Waters of Taiwan. J. Mar. Sci. Eng. 2020, 8, 217. [CrossRef]

47. Chen, W.-B.; Lin, L.-Y.; Jang, J.-H.; Chang, C.-H. Simulation of Typhoon-Induced Storm Tides and Wind Waves for the Northeastern Coast of Taiwan Using a Tide-Surge-Wave Coupled Model. Water 2017, 9, 549. [CrossRef]

48. Hsiao, S.-C.; Wu, H.-L.; Chen, W.-B.; Chang, C.-H.; Lin, L.-Y. On the Sensitivity of Typhoon Wave Simulations to Tidal Elevation and Current. J. Mar. Sci. Eng. 2020, 8, 731. [CrossRef]

49. Zhang, H.; Sheng, J. Estimation of extreme sea levels over the eastern continental shelf of North America. J. Geophys. Res. Oceans 2013, 118, 6253-6273. [CrossRef]

50. Muis, S.; Verlaan, M.; Winsemius, H.C.; Aerts, J.C.J.H.; Ward, P.J. A global reanalysis of storm surges and extreme sea levels. Nat. Commun. 2017, 7, 11969. [CrossRef] [PubMed] 
51. Marsooli, R.; Lin, N. Numerical Modeling of Historical Storm Tides and Waves and Their Interactions Along the U.S. East and Gulf Coasts. J. Geophys. Res. Oceans 2018, 123, 3844-3874. [CrossRef]

52. Amaechi, C.V.; Wang, F.; Hou, X.; Ye, J. Strength of submarine hoses in Chinese-lantern configuration from hydrodynamic loads on CALM buoy. Ocean. Eng. 2019, 171, 429-442. [CrossRef]

53. Zu, T.; Gana, J.; Erofeevac, S.Y. Numerical study of the tide and tidal dynamics in the South China Sea. Deep Sea Res. Part. I 2008, 55, 137-154. [CrossRef]

54. Boronowski, S.; Wild, P.; Rowe, A.; G. Cornelis van Kooten, C.G. Integration of wave power in Haida Gwaii. Renew. Energy 2010, 35, 2415-2421. [CrossRef]

55. Sierra, J.P.; Moss, A.; Gonzale-Marco, D. Wave energy resource assessment in Menorca (Spain). Renew. Energy 2014, 71, 51-60. [CrossRef]

56. Sierra, J.P.; Casas-Prat, M.; Campins, E. Impact of climate change on wave energy resource: The case of Menorca (Spain). Renew. Energy 2017, 101, 275-285. [CrossRef]

57. Su, W.-R.; Chen, H.; Chen, W.-B.; Chang, C.-H.; Lin, L.-Y.; Jang, J.-H.; Yu, Y.-C. Numerical investigation of wave energy resources and hotspots in the surrounding waters of Taiwan. Renew. Energy 2018, 118, 814-824. [CrossRef]

58. Gonçalves, M.; Martinho, P.; Guedes Soares, C. Wave energy assessment based on a 33-year hindcast for the Canary Islands. Renew. Energy 2020, 152, 259-269. [CrossRef]

59. Cornett, A. A global wave energy resource assessment. In Proceedings of the 18th International Offshore and Polar Engineering Conference, Vancouver, BC, Canada, 6-11 July 2008.

60. Wan, Y.; Fan, C.; Zhang, J.; Meng, J.; Dai, Y.; Li, L.; Sun, W.; Zhou, P.; Wang, J.; Zhang, Z. Wave Energy Resource Assessment off the Coast of China around the Zhoushan Islands. Energies 2017, 10, 1320. [CrossRef]

61. Zheng, C.W.; Pan, J.; Li, J.X. Assessing the China Sea wind energy and wave energy resources from 1988 to 2009. Ocean. Eng. 2013, 65, 39-48.

62. Kamranzad, B.; Etemad-Shahidi, A.; Chegini, V. Developing an optimum hotspot identifier for wave energy extracting in the northern Persian Gulf. Renew. Energy 2017, 114, 59-71. [CrossRef]

63. Lopez, I.; Andreu, J.; Ceballos, S.; Martínez De Alegría, I.; Kortabarria, I. Review of wave energy technologies and the necessary power-equipment. Renew. Sustain. Energy Rev. 2013, 27, 413-434. [CrossRef]

64. Lavidas, G.; Venugopal, V. A 35-year high-resolution wave atlas for nearshore energy production and economics at the Aegean Sea. Renew. Energy 2017, 103, 401-417. [CrossRef]

65. Amarouche, K.; Akpınar, A.; El Islam Bachari, N.; Houma, F. Wave energy resource assessment along the Algerian coast based on 39-year wave hindcast. Renew. Energy 2020, 153, 840-860. [CrossRef]

66. Atan, R.; Goggins, J.; Nash, S. A Detailed Assessment of the Wave Energy Resource at the Atlantic Marine Energy Test Site. Energies 2016, 9, 967. [CrossRef]

67. Tao, S.Y.; Chen, L.X. A review of recent research on East Asian summer monsoon in China. In Monsoon Meteorology; Chang, C.P., Krishnamurti, T.N., Eds.; Oxford University Press: New York, NY, USA, 1987.

68. Boyle, J.S.; Chen, G.T.J. Synoptic aspects of the wintertime East Asian monsoon. In Monsoon Meteorology; Chang, C.P., Krishnamurti, T.N., Eds.; Oxford University Press: New York, NY, USA, 1987. 